\title{
A Practical Method for Enantioselective Synthesis of All-Carbon Quaternary Stereogenic Centers through NHC-Cu-Catalyzed Conjugate Additions of Alkyl- and Arylzinc Reagents to $\beta$-Substituted Cyclic Enones
}

\author{
Kang-sang Lee, M. Kevin Brown, Alexander W. Hird, and Amir H. Hoveyda* \\ Department of Chemistry, Merkert Chemistry Center, \\ Boston College, Chestnut Hill, Massachusetts 02467
}

\section{SUPPORTING INFORMATION}

General. Infared (IR) spectra were recorded on a Nicolet 210 spectrophotometer, $v_{\max }$ in $\mathrm{cm}^{-1}$. Bands are characterized as broad (br), strong (s), medium (m), and weak (w). ${ }^{1} \mathrm{H}$ NMR spectra were recorded on a Varian Unity INOVA $400(400 \mathrm{MHz})$ spectrometer. Chemical shifts are reported in $\mathrm{ppm}$ from tetramethylsilane with the solvent resonance as the internal standard $\left(\mathrm{CDCl}_{3}: \delta 7.26 \mathrm{ppm}\right)$. Data are reported as follows: chemical shift, integration, multiplicity ( $\mathrm{s}=$ singlet, $\mathrm{d}=$ doublet, $\mathrm{t}=$ triplet, $\mathrm{q}=$ quartet, $\mathrm{br}=$ broad, $\mathrm{m}=$ multiplet , and coupling constants

$(\mathrm{Hz}) .{ }^{13} \mathrm{C}$ NMR spectra were recorded on a Varian Unity INOVA $400(100 \mathrm{MHz})$ spectrometer with complete proton decoupling. Chemical shifts are reported in ppm from tetramethylsilane with the solvent resonance as the internal standard $\left(\mathrm{CDCl}_{3}: \delta 77.16 \mathrm{ppm}\right)$. High-resolution mass spectrometry was preformed on a Micromass LCT ESI-MS (positive mode) at the Mass Spectrometry Facility, Boston College and at the University of Illinois Mass Spectrometry Laboratories (Urbana, Illinois). Elemental microanalyses were performed at Robertson Microlit Laboratories (Madison, NJ). Enantiomer ratios were determined by chiral GLC analysis (Alltech Associated Chiraldex GTA column (30 m x $0.25 \mathrm{~mm}$ ) and Betadex 120 column (30 m x 0.25 $\mathrm{mm}$ ), and by chiral HPLC analysis (Chiral Technologies Chiralpak AS column, $25 \mathrm{~cm} \times 0.46$ $\mathrm{cm}$ ) in comparison with authentic racemic materials. Optical rotations were measured on a Rudolph Research Analytical Autopol IV Polarimeter.

Unless otherwise noted, all reactions were carried out with distilled and degassed solvents under an atmosphere of dry $\mathrm{N}_{2}$ in oven- $\left(135^{\circ} \mathrm{C}\right)$ and flame-dried glassware with standard dry box or vacuum-line techniques. Solvents were purified under a positive pressure of dry Ar by a modified Innovative Technologies purification system: toluene and benzene were purified by being passed through a copper oxide and alumina column; $\mathrm{CH}_{2} \mathrm{Cl}_{2}$ and $\mathrm{Et}_{2} \mathrm{O}$ were purged with $\mathrm{Ar}$ and purified by being passed through two alumina columns. THF was purified by distillation from sodium benzophenone ketal immediately prior to use. Chloroform and $\mathrm{Et}_{3} \mathrm{~N}$ were purified by distillation over $\mathrm{CaH}_{2}$. Dioxane was distilled over $\mathrm{Na}$. All work-up and purification procedures were carried out with reagent solvents in air. All reagent solvents were purchased from Doe and Ingalls. Diethylzinc (neat) and $\mathrm{Pd}(\mathrm{OAc})_{2}(99.9+\%)$ were purchased from Aldrich and used as received. Di- $n$-butylzinc was purchased from Fluka (1.0 M in heptane) and used as 
received. Diphenylzinc was purchased from Strem Inc. (white solid) and used without purification. ${ }^{1}$ Copper (I) triflate benzene complex (2:1) was prepared by previously reported methods. ${ }^{2} \mathrm{Cu}_{2} \mathrm{O}(99.9 \%)$ was purchased from Strem and used without purification. Triflic anhydride was prepared by distillation of triflic acid (Aldrich) over $\mathrm{P}_{2} \mathrm{O}_{5}$ (Aldrich). 3-Methyl-2cyclohexenone was purchased from Aldrich and distilled prior to use. Di-4trifluoromethylphenyl zinc was prepared by previously reported methods. ${ }^{3}$ All other substrates were prepared by established methods. ${ }^{4}$ Chiral Ag- and Cu-based complexes were prepared according to published methods. ${ }^{5}$ Phenylboronic acid (Aldrich) was re-crystallized from water. Triphenylphosphine (Strem) was re-crystallized from $\mathrm{Et}_{2} \mathrm{O}$.

Representative experimental procedure for Cu-catalyzed conjugate addition of (alkyl) $2 \mathrm{Zn}$ reagents: An oven-dried $13 \times 100 \mathrm{~mm}$ test tube charged with chiral Ag complex 4 (5.0 $\mathrm{mg}, 0.0044 \mathrm{mmol}),(\mathrm{CuOTf})_{2} \cdot \mathrm{C}_{6} \mathrm{H}_{6}(2.1 \mathrm{mg}, 0.0041 \mathrm{mmol})$ and 3-methyl-2-cyclohexenone (18 $\mathrm{mg}, 0.16 \mathrm{mmol}$ ) was weighed out under an $\mathrm{N}_{2}$ atmosphere in a glove box. The test tube was sealed with a septum and wrapped with parafilm before removal from the glove box. Diethyl ether $\left(1.0 \mathrm{~mL}\right.$ ) was added at $22{ }^{\circ} \mathrm{C}$ (syringe); the resulting solution was allowed to stir for $10 \mathrm{~min}$. Diethylzinc $(50 \mu \mathrm{L}, 0.49 \mathrm{mmol})$ was slowly added to the mixture at $-78{ }^{\circ} \mathrm{C}$; during the addition of $\mathrm{Et}_{2} \mathrm{Zn}$ the reaction turned dark brown. After the addition of $\mathrm{Et}_{2} \mathrm{Zn}$, the solution was allowed to warm to $-30{ }^{\circ} \mathrm{C}$. After $6 \mathrm{~h}$ at $-30^{\circ} \mathrm{C}$, the reaction was quenched by the addition of a saturated aqueous solution of ammonium chloride $(1 \mathrm{~mL})$ and then immediately $\mathrm{H}_{2} \mathrm{O}(1 \mathrm{~mL})$. The mixture was washed with $\mathrm{Et}_{2} \mathrm{O}(3 \times 1 \mathrm{~mL})$ and the combined organic layers were passed through a short plug $(4 \mathrm{~cm} \times 1 \mathrm{~cm})$ of silica gel eluted with $\mathrm{Et}_{2} \mathrm{O}$. The volatiles were removed in vacuo and the resulting dark brown oil was purified by silica gel column chromatography (hexanes/Et ${ }_{2} \mathrm{O}: 10 / 1$ ) to afford $21.1 \mathrm{mg}(0.150 \mathrm{mmol}, 92.5 \%$ yield $)$ of $\mathbf{6}$ as a colorless oil. Important note: To ensure high efficiency and enantioselectivity, reactions must be set up in exactly the order described above.

\section{Representative procedure for $\mathrm{Cu}$-Catalyzed conjugate addition of $\mathbf{E t}_{2} \mathrm{Zn}$ carried out on} bench top and performed in undistilled diethyl ether: A $13 \times 100 \mathrm{~mm}$ test tube charged with

(1) It is critical that high quality $\mathrm{Ph}_{2} \mathrm{Zn}$ is used. For example, use of reagents purchased from Aldrich (brown solid) leads to highly inefficient transformations. Development of reliable in situ methods for preparation of alkyl- and arylzinc reagents is in progress and will be disclosed shortly.

(2) Salomon, R. G.; Kochi, J. K. J. Am. Chem. Soc. 1973, 95, 1889-1897.

(3) Chisholm, M. H.; Galluci, J. C.; Yin, H.; Zhen, H. Inorg. Chem. 2005, 44, 4777-4785.

(4) (a) Fu, X.; Zhang, S.; Yin, J.; Schumacher, D. P. Tetrahedron Lett. 2002, 43, 6673-6676. (b) Dauben, W. G.; Michno, D. M. J. Org. Chem. 1977, 42, 682-685. (c) Dittami, J. P.; Nie, X. Y.; Nie, H.; Ramanathan, H.; Breining, S. J. Org. Chem. 1991, 56, 5572-5578.

(5) (a) Larsen, A. O.; Leu, W.; Nieto-Oberhuber, C.; Campbell, J. E.; Hoveyda, A. H. J. Am. Chem. Soc. 2004, 126, 11130-11131. (b) Van Veldhuizen, J. J.; Campbell, J. E.; Giudici, R. E.; Hoveyda, A. H. J. Am. Chem. Soc. 2005, $127,6877-6882$. 
chiral Ag complex 4 (4.5 mg, $0.0036 \mathrm{mmol})$, (CuOTf) $)_{2} \bullet$ toluene $(1.9 \mathrm{mg}, 0.0036 \mathrm{mmol})$, and 3methyl-2-cyclohexenone $(16 \mathrm{mg}, 0.14 \mathrm{mmol})$ weighed out on the bench top in air, was sealed with a septum, wrapped with parafilm, and purged with $\mathrm{N}_{2}$. Undistilled $\mathrm{Et}_{2} \mathrm{O}(1.0 \mathrm{~mL})$ was added at $22{ }^{\circ} \mathrm{C}$ (syringe); the resulting solution was allowed to stir for $10 \mathrm{~min}$. Diethylzinc (45 $\mu \mathrm{L}, 0.43 \mathrm{mmol}$ ) was slowly added to the mixture at $-78{ }^{\circ} \mathrm{C}$; during the addition of diethylzinc the reaction turned dark brown. After the addition of $\mathrm{Et}_{2} \mathrm{Zn}$, the solution was allowed to warm to $-30{ }^{\circ} \mathrm{C}$. After $6 \mathrm{~h}$ at $-30^{\circ} \mathrm{C}$, the reaction was quenched by the addition of a saturated solution of aqueous ammonium chloride $(1.0 \mathrm{~mL})$ and then immediately $\mathrm{H}_{2} \mathrm{O}(1.0 \mathrm{~mL})$. The mixture was washed with $\mathrm{Et}_{2} \mathrm{O}(3 \times 1 \mathrm{~mL})$ and passed through a short plug of silica eluted with the same solvent. The volatiles were removed in vacuo to afford a light yellow oil, which was purified by silica gel column chromatography (hexanes/ $\left.\mathrm{Et}_{2} \mathrm{O}: 10 / 1\right)$ to afford $17.0 \mathrm{mg}(0.121 \mathrm{mmol}, 83.3 \%$ yield) of cyclic ketone 6 as a colorless oil. Important note: To ensure high efficiency and enantioselectivity reactions must be set up in exactly the order described above.

(R)-(+)-3-Ethyl-3-methylcyclohexanone (6). IR (neat): 2962 (s), 2936 (s), 2879 (m), 2855 (w), $1715(\mathrm{~s}), 1464(\mathrm{~m}) \mathrm{cm}^{-1} ;{ }^{1} \mathrm{H}$ NMR $\left(400 \mathrm{MHz}, \mathrm{CDCl}_{3}\right): \delta 2.27(2 \mathrm{H}, \mathrm{dd}, J=6.8,6.8 \mathrm{~Hz}), 2.18(1 \mathrm{H}$, d, $J=13.6 \mathrm{~Hz}), 2.09(1 \mathrm{H}, \mathrm{d}, J=13.6 \mathrm{~Hz}), 1.90-1.83(2 \mathrm{H}, \mathrm{m}), 1.66-1.50(2 \mathrm{H}, \mathrm{m}), 1.35-1.29(2 \mathrm{H}$, m), $0.90(3 \mathrm{H}, \mathrm{s}), 0.84(3 \mathrm{H}, \mathrm{t}, J=7.6 \mathrm{~Hz}) ;{ }^{13} \mathrm{C} \mathrm{NMR}\left(100 \mathrm{MHz}, \mathrm{CDCl}_{3}\right): \delta 212.4,53.4,41.0,38.7$, 35.4, 34.0, 24.4, 22.1 7.7; Anal Calcd for $\mathrm{C}_{9} \mathrm{H}_{16} \mathrm{O}$ : C, 77.09; H, 11.50; Found C, 76.86; H, 11.25. HRMS Calcd for $\mathrm{C}_{9} \mathrm{H}_{16} \mathrm{O}\left(\mathrm{EI}^{+}\right)$: 140.1201, Found: 140.1196. Optical rotation: $[\alpha]_{\mathrm{D}}^{20}+8.0$ $\left(c=1.0, \mathrm{CHCl}_{3}\right)$ for an $87 \%$ ee sample.

Optical purity was determined by chiral GLC analysis in comparison with authentic racemic material (95\% ee shown below; $\beta$-dex chiral column, $80^{\circ} \mathrm{C}, 15 \mathrm{psi}$ ).
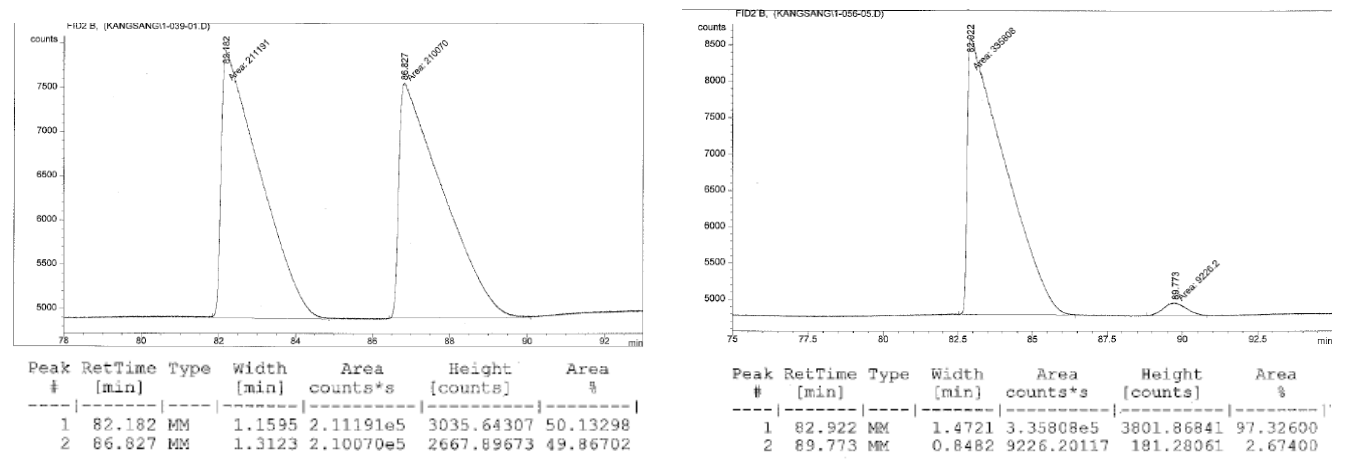

(R)-3-Butyl-3-methylcyclohexanone (7). IR (neat): 2957 (s), 2931 (s), 2870 (m), 2860 (m), 1715 (s), 1467 (w), 1457 (w) cm ${ }^{-1} ;{ }^{1} \mathrm{H}$ NMR (400 MHz, $\left.\mathrm{CDCl}_{3}\right): \delta 2.26(2 \mathrm{H}, \mathrm{dd}, J=7.2,7.2 \mathrm{~Hz}$ ), $2.17(1 \mathrm{H}, \mathrm{d}, J=13.6 \mathrm{~Hz}), 2.09(1 \mathrm{H}, \mathrm{d}, J=13.6 \mathrm{~Hz}), 1.88-1.81(2 \mathrm{H}, \mathrm{m}), 1.65-1.48(2 \mathrm{H}, \mathrm{m}), 1.29$ $1.17(6 \mathrm{H}, \mathrm{m}), 0.90(6 \mathrm{H}, \mathrm{m}) ;{ }^{13} \mathrm{C} \mathrm{NMR}\left(100 \mathrm{MHz} \mathrm{CDCl}_{3}\right): \delta$ 212.7, 54.0, 41.4, 41.2, 38.7, 36.0, 25.7, 25.3, 23.5, 22.3, 14.2. HRMS Calcd for $\mathrm{C}_{11} \mathrm{H}_{20} \mathrm{O}\left(\mathrm{EI}^{+}, \mathrm{M}+\mathrm{H}\right)$ : 169.1592, Found: 169.1593. Optical rotation: $[\alpha]_{\mathrm{D}}{ }^{20}+1.15\left(c=1.00, \mathrm{CHCl}_{3}\right)$ for an $86 \%$ ee sample. 
Optical purity was determined by chiral GLC analysis in comparison with authentic racemic material ( $86 \%$ ee sample below; $\beta$-dex column, $120{ }^{\circ} \mathrm{C}, 15 \mathrm{psi}$ ).
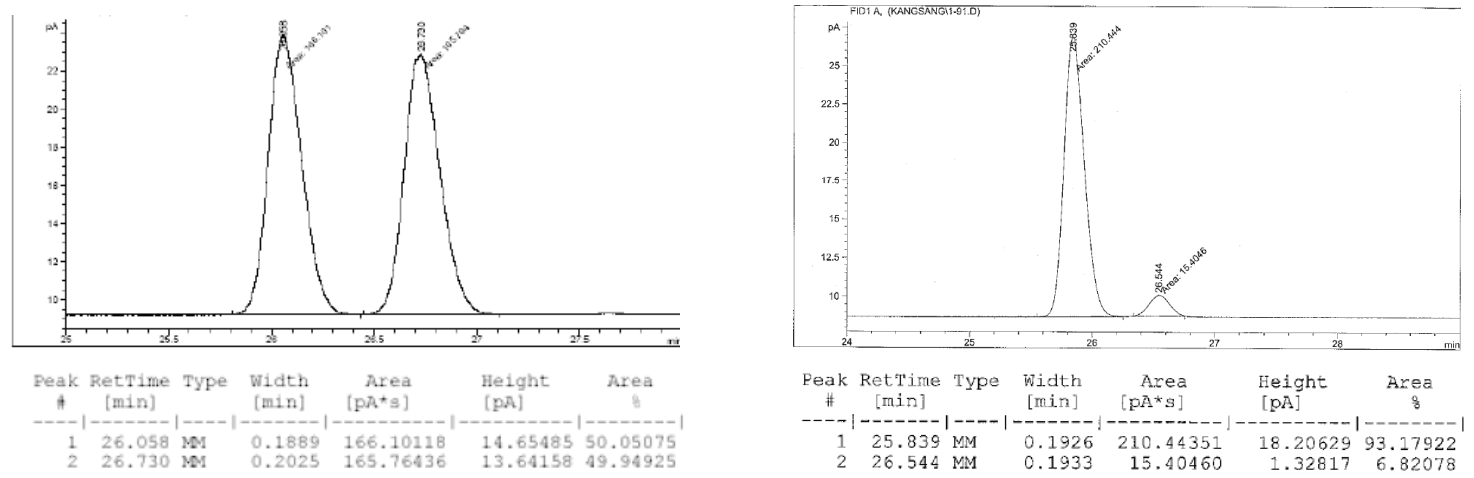

(R)-3-Ethyl-3-(4-pentenyl)cyclohexanone (8). IR (neat): 3087 (w), 2936 (s), 1721 (s), 1646 (w), 1463 (m), 1419 (m), 1388 (w), 1350 (w), 1318 (w), 1230 (w), 1092 (w), 1004 (m), 903 (m) cm ${ }^{-1}$. ${ }^{1} \mathrm{H}$ NMR $\left(\mathrm{CDCl}_{3}, 400 \mathrm{MHz}\right): \delta 5.57$ (1H, dddd, $\left.J=17.2,10.4,6.8,6.8 \mathrm{~Hz}\right), 5.00-4.91(2 \mathrm{H}, \mathrm{m})$, $2.25(2 \mathrm{H}, \mathrm{t}, J=6.8 \mathrm{~Hz}), 2.12(2 \mathrm{H}, \mathrm{s}), 2.02-1.96(2 \mathrm{H}, \mathrm{m}), 1.84-1.78(2 \mathrm{H}, \mathrm{m}), 1.57-1.54(2 \mathrm{H}, \mathrm{m})$, 1.31-1.18 (6H, m), $0.76(3 \mathrm{H}, \mathrm{t}, J=7.2 \mathrm{~Hz}) .{ }^{13} \mathrm{C} \mathrm{NMR}\left(\mathrm{CDCl}_{3}, 100 \mathrm{MHz}\right): \delta 212.8,138.8,114.9$, 52.1, 41.3, 41.1, 36.1, 34.5, 33.6, 29.7, 22.4, 21.9, 7.6. HRMS calcd for $\mathrm{C}_{13} \mathrm{H}_{22} \mathrm{O}$ : 194.1671, Found: 194.1675. Optical rotation: $[\alpha]_{\mathrm{D}}{ }^{20}+4.87\left(c=1.29, \mathrm{CHCl}_{3}\right)$ for an $82 \%$ ee sample.

Optical purity was determined by chiral GLC analysis in comparison with authentic racemic material ( $84 \%$ ee sample below; conditions: $\beta$-dex column, $130{ }^{\circ} \mathrm{C}, 15 \mathrm{psi}$ ).
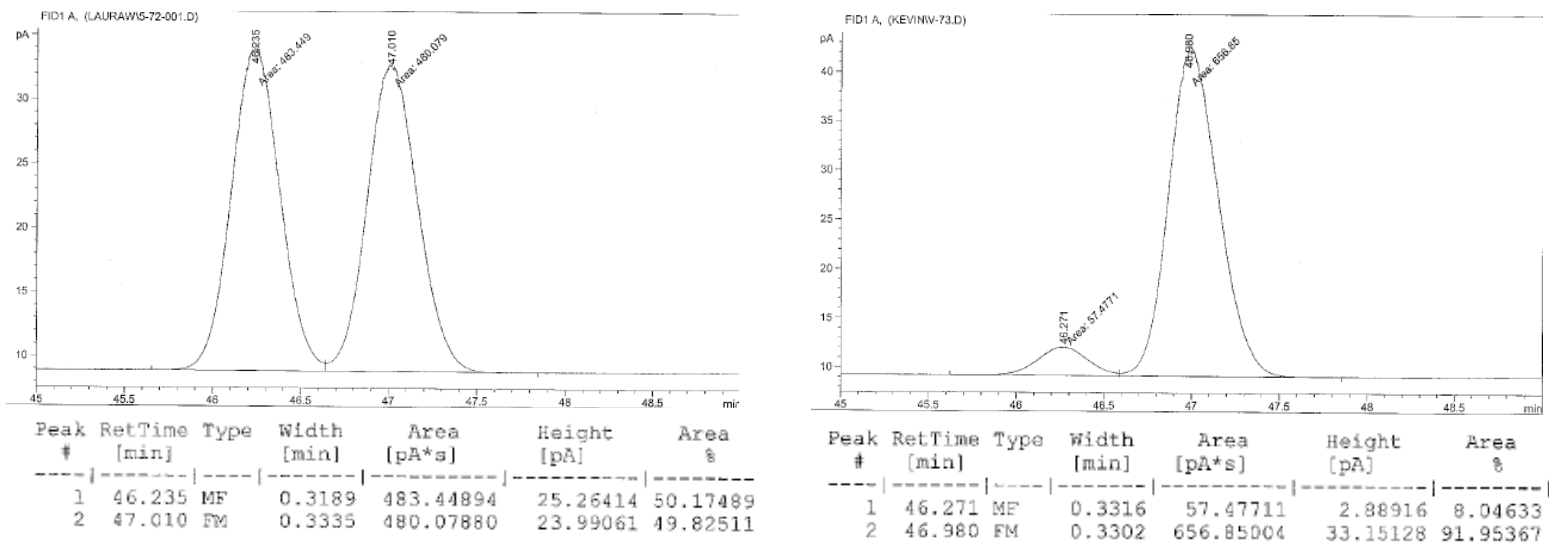

(S)-3-Ethyl-3-(2-phenyl ethynyl)cyclohexanone (9). IR (neat): 2965 (m), 2926 (m), 2874 (w), 2853 (w), 2359 (w), 2338 (w), 1716 (s), 1597 (w) cm ${ }^{-1} ;{ }^{1} \mathrm{H}$ NMR (400 MHz, $\mathrm{CDCl}_{3}$ ): $\delta$ 7.37-7.33 $(2 \mathrm{H}, \mathrm{m}), 7.27-7.23(3 \mathrm{H}, \mathrm{m}), 2.59(1 \mathrm{H}, \mathrm{ddd}, J=14.0,2.0,2.0 \mathrm{~Hz}), 2.44-2.38(1 \mathrm{H}, \mathrm{m}), 2.30-2.10$ $(3 \mathrm{H}, \mathrm{m}), 2.06-1.96(2 \mathrm{H}, \mathrm{m}), 1.69-1.58(3 \mathrm{H}, \mathrm{m}), 1.07(3 \mathrm{H}, \mathrm{t}, J=7.6 \mathrm{~Hz}) ;{ }^{13} \mathrm{C} \mathrm{NMR}(100 \mathrm{MHz}$, $\left.\mathrm{CDCl}_{3}\right): \delta 209.6,131.9,128.3,128.1,123.5,92.1,85.1,52.6,41.5,41.2,35.9,35.0,23.0,9.1$; HRMS Calcd for $\mathrm{C}_{16} \mathrm{H}_{18} \mathrm{O}\left(\mathrm{EI}^{+}\right)$: 226.1358, Found: 226.1363. Optical rotation: $[\alpha]_{\mathrm{D}}{ }^{20}+39.87$ $\left(c=1.000, \mathrm{CHCl}_{3}\right)$ for a $74 \%$ ee sample. 
Optical purity was determined by chiral GLC analysis in comparison with authentic racemic material. ( $74 \%$ ee sample below; conditions: $\beta$-dex column, $140{ }^{\circ} \mathrm{C}, 15 \mathrm{psi}$ ).
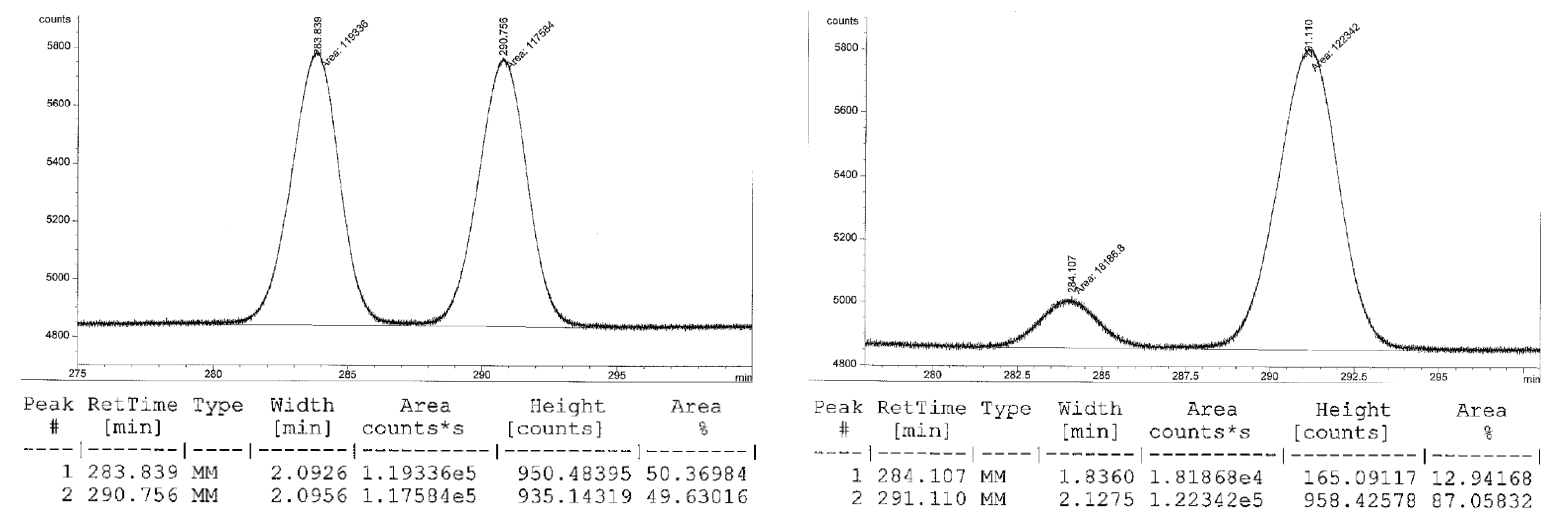

(S)-3-Ethyl-3-phenylcyclohexanone (10): IR (neat): 3089 (w), 3058 (w), 3031 (w), 3024 (w) 2962 (s), 2934 (s), 2877 (m), 2355 (w), 2332 (w), 1715 (s), 1601 (w), 1498 (m), 1460 (m), 1445 (s) $\mathrm{cm}^{-1}$; ${ }^{1} \mathrm{H}$ NMR $\left(400 \mathrm{MHz}, \mathrm{CDCl}_{3}\right): \delta$ 7.32-7.27 (2H, m), 7.25-7.22 (2H, m), 7.20-7.15 (1H, m), $2.90(1 \mathrm{H}, \mathrm{d}, J=14.4 \mathrm{~Hz}), 2.40(1 \mathrm{H}, \mathrm{d}, J=14.4 \mathrm{~Hz}), 2.30-2.26(2 \mathrm{H}, \mathrm{m}), 2.19-2.13(1 \mathrm{H}, \mathrm{m}), 2.00-$ $1.93(1 \mathrm{H}, \mathrm{m}), 1.84-1.54(4 \mathrm{H}, \mathrm{m}), 0.58(3 \mathrm{H}, \mathrm{t}, J=7.6 \mathrm{~Hz}) ;{ }^{13} \mathrm{C} \mathrm{NMR}\left(100 \mathrm{MHz}, \mathrm{CDCl}_{3}\right): \delta 211.6$, 145.0, 128.6, 126.7, 126.2, 50.7, 46.6, 41.2, 36.4, 35.8, 21.7, 8.1; HRMS Calcd for $\mathrm{C}_{14} \mathrm{H}_{18} \mathrm{O}$ $\left(\mathrm{EI}^{+}\right): 202.1358$, Found: 202.1362 . Optical rotation: $[\alpha]_{\mathrm{D}}{ }^{20}+63.77\left(c=1.000, \mathrm{CHCl}_{3}\right)$ for a $94 \%$ ee sample.

Optical purity was determined by chiral GLC analysis in comparison with authentic racemic material. (90\% ee sample below; conditions: $\beta$-dex column, $140{ }^{\circ} \mathrm{C}, 15 \mathrm{psi}$ ).
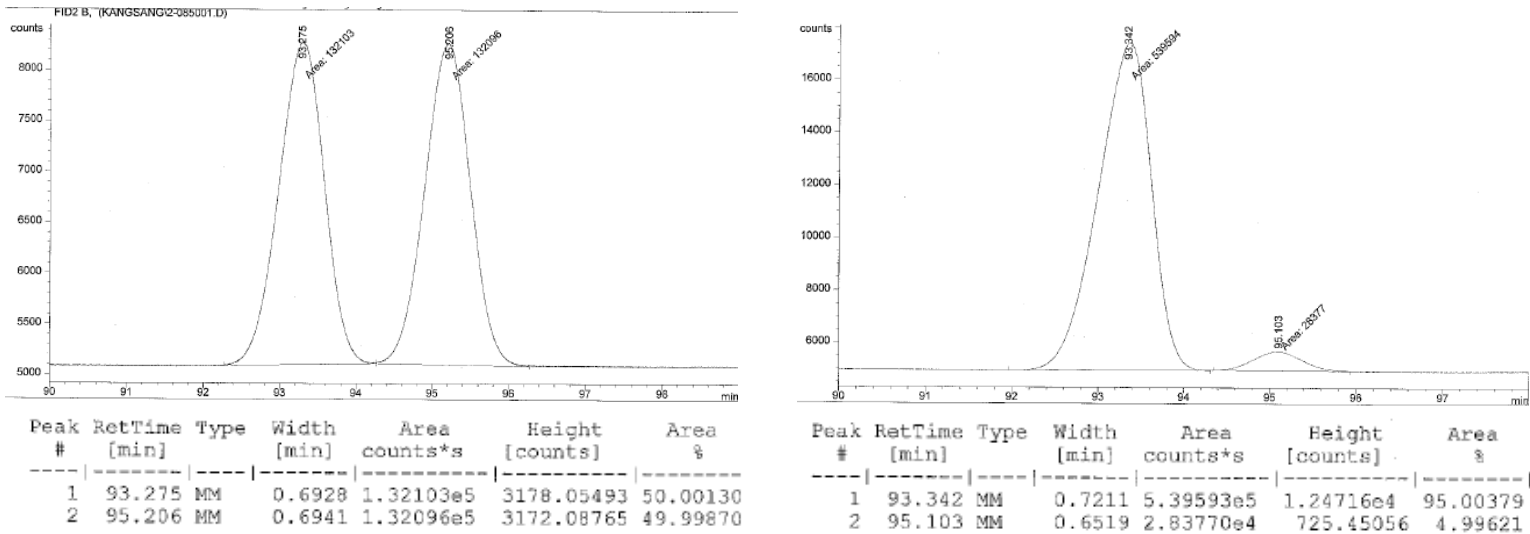

(R)-3-Ethyl-3-methylcycloheptanone (11). IR (neat): 2964 (m), 2929 (s), 2882 (w), 2861 (w), 1697 (s), 1464 (w) cm ${ }^{-1} ;{ }^{1} \mathrm{H}$ NMR (400 MHz, $\left.\mathrm{CDCl}_{3}\right): \delta 2.51(1 \mathrm{H}, \mathrm{d}, J=12.0 \mathrm{~Hz}), 2.41-2.37(2 \mathrm{H}$, m), $2.35(1 \mathrm{H}, \mathrm{d}, J=12.0 \mathrm{~Hz}), 1.78-1.47(6 \mathrm{H}, \mathrm{m}), 1.34-1.23(2 \mathrm{H}, \mathrm{m}), 0.86(3 \mathrm{H}, \mathrm{s}), 0.83(3 \mathrm{H}, \mathrm{t}, J$ $=7.6 \mathrm{~Hz}) ;{ }^{13} \mathrm{C} \mathrm{NMR}\left(100 \mathrm{MHz}, \mathrm{CDCl}_{3}\right): \delta 214.4,54.2,44.1,42.2,35.4,35.0,25.5,24.8,24.3$, 8.0; HRMS Calcd for $\mathrm{C}_{10} \mathrm{H}_{18} \mathrm{O}\left(\mathrm{EI}^{+}\right)$: 154.1358, Found: 154.1356. Optical rotation: $[\alpha]_{\mathrm{D}}{ }^{20}+17.06$ $\left(c=1.000, \mathrm{CHCl}_{3}\right)$ for an $85 \%$ ee sample. 
Optical purity was determined by chiral GLC analysis in comparison with authentic racemic material ( $85 \%$ ee sample below; conditions: $\beta$-dex column, $80{ }^{\circ} \mathrm{C}, 15 \mathrm{psi}$ ).
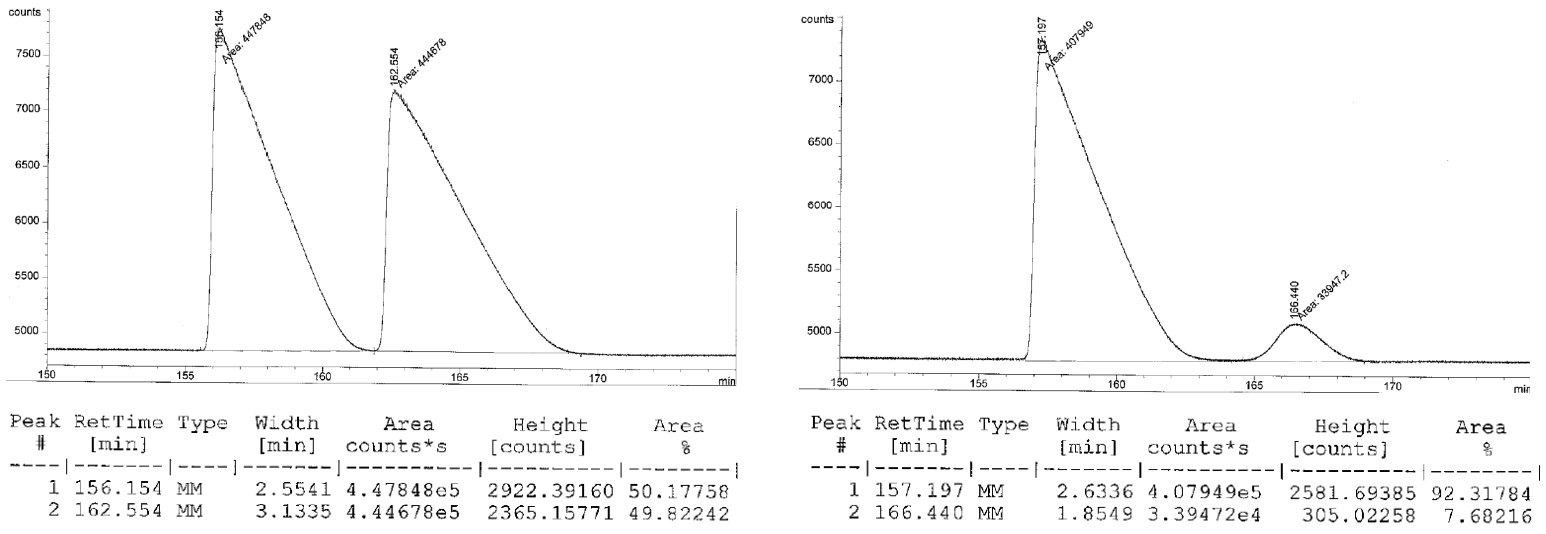

(R)-3-Butyl-3-methylcycloheptanone (12). IR (neat): 2958 (s), 2934 (s), 2871 (m), 2859 (m), $1701(\mathrm{~s}), 1461(\mathrm{~m}) \mathrm{cm}^{-1} ;{ }^{1} \mathrm{H}$ NMR $\left(400 \mathrm{MHz}, \mathrm{CDCl}_{3}\right): \delta 2.51(1 \mathrm{H}, \mathrm{d}, J=12.4 \mathrm{~Hz}), 2.41-2.35(3 \mathrm{H}$, $\mathrm{m}), 1.77-1.57(5 \mathrm{H}, \mathrm{m}), 1.52-1.47(1 \mathrm{H}, \mathrm{m}), 1.23-1.17(6 \mathrm{H}, \mathrm{m}), 0.90-0.86(6 \mathrm{H}, \mathrm{m}) ;{ }^{13} \mathrm{C}$ NMR $(100$ $\left.\mathrm{MHz}, \mathrm{CDCl}_{3}\right): \delta 214.5,55.0,44.1,42.7,42.4,35.3,26.2,25.8,24.8,24.3,23.5,14.2$; Anal Calcd for $\mathrm{C}_{12} \mathrm{H}_{22} \mathrm{O}$ : C, 79.06; H, 12.16; Found C, 78.89; H, 12.14; HRMS Calcd for $\mathrm{C}_{12} \mathrm{H}_{22} \mathrm{O}\left(\mathrm{EI}^{+}\right)$: 182.1671, Found: 182.1668. Optical rotation: $[\alpha]_{\mathrm{D}}{ }^{20}+10.0\left(c=1.00, \mathrm{CHCl}_{3}\right)$ for a $77 \%$ ee sample.

Optical purity was determined by chiral GLC analysis in comparison with authentic racemic material (77\% ee sample below; conditions: $\beta$-dex column, $90{ }^{\circ} \mathrm{C}, 15 \mathrm{psi}$ ).
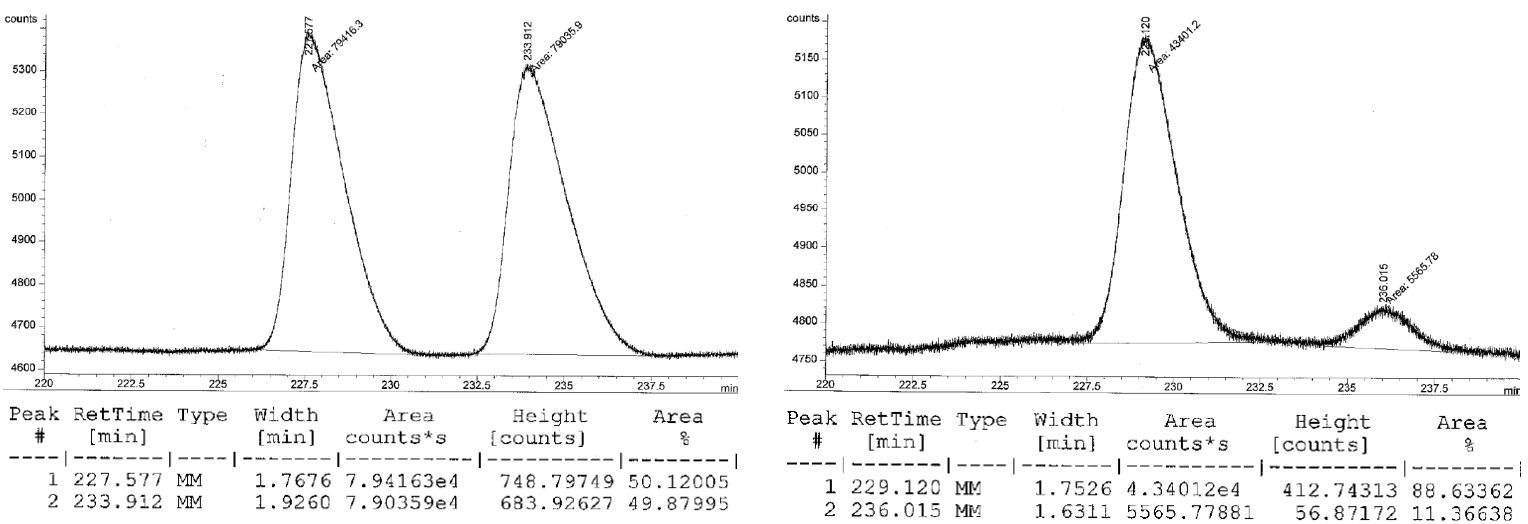

(S)-3-Butyl-3-ethylcycloheptanone (13). IR (neat): 2958 (s), 2927 (s), 2871 (m), 2861 (m), $1697(\mathrm{~m}), 1458(\mathrm{~m}) \mathrm{cm}^{-1} ;{ }^{1} \mathrm{H}$ NMR $\left(400 \mathrm{MHz}, \mathrm{CDCl}_{3}\right): \delta 2.43(2 \mathrm{H}, \mathrm{s}), 2.39(2 \mathrm{H}, \mathrm{t}, J=6.2 \mathrm{~Hz})$, 1.77-1.72 (2H, m), 1.64-1.60 (2H, m), 1.57-1.53 (2H, m), 1.34-1.13 (8H, m), 0.88 (3H, t, J= 7.0 $\mathrm{Hz}), 0.79(3 \mathrm{H}, \mathrm{t}, J=7.6 \mathrm{~Hz}) ;{ }^{13} \mathrm{C} \mathrm{NMR}\left(100 \mathrm{MHz}, \mathrm{CDCl}_{3}\right): \delta 214.8,53.5,44.1,40.1,37.7,37.4$, 30.7, 25.2, 24.4, 24.4, 23.6, 14.2, 7.6; HRMS Calcd for $\mathrm{C}_{13} \mathrm{H}_{24} \mathrm{O}\left(\mathrm{EI}^{+}\right)$: 196.1827, Found: 196.1827. Optical rotation: $[\alpha]_{\mathrm{D}}{ }^{20}+5.98\left(c=1.00, \mathrm{CHCl}_{3}\right)$ for a $76 \%$ ee sample. 
Optical purity was determined by chiral GLC analysis in comparison with authentic racemic material ( $76 \%$ ee sample below; conditions: $\beta$-dex column, $90{ }^{\circ} \mathrm{C}(300 \mathrm{~min}), 20{ }^{\circ} \mathrm{C} / \mathrm{min}$ to $140^{\circ} \mathrm{C}$ (10 min), 15 psi).
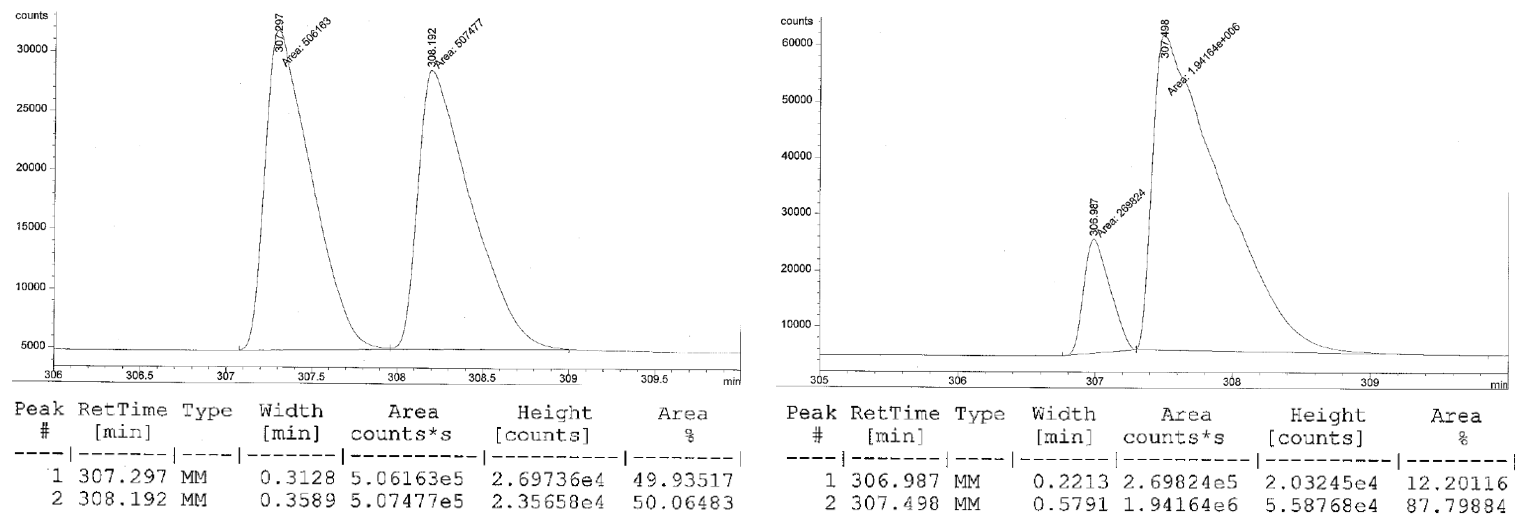

(R)-3-Ethyl-3-methylcyclooctanone (14). IR (neat): 2955 (m), 2924 (s), 2875 (w), 2852 (w), 1695 (s), $1470(\mathrm{w}) \mathrm{cm}^{-1} ;{ }^{1} \mathrm{H}$ NMR (400 MHz, $\left.\mathrm{CDCl}_{3}\right): \delta 2.39(1 \mathrm{H}, \mathrm{d}, J=10.8 \mathrm{~Hz}), 2.29$ (2H, ddd, $J=8.0,4.0,4.0 \mathrm{~Hz}), 2.17(1 \mathrm{H}, \mathrm{d}, J=10.8 \mathrm{~Hz}), 1.95-1.87(2 \mathrm{H}, \mathrm{m}), 1.53-1.47(2 \mathrm{H}, \mathrm{m}), 1.42-1.25$ $(6 \mathrm{H}, \mathrm{m}), 0.91(3 \mathrm{H}, \mathrm{s}), 0.84(3 \mathrm{H}, \mathrm{t}, J=7.6 \mathrm{~Hz}) ;{ }^{13} \mathrm{C} \mathrm{NMR}\left(100 \mathrm{MHz}, \mathrm{CDCl}_{3}\right): \delta 215.5,48.8,45.5$, 39.0, 37.0, 34.7, 29.1, 25.6, 22.0, 20.3, 8.3; HRMS Calcd for $\mathrm{C}_{11} \mathrm{H}_{20} \mathrm{O}\left(\mathrm{EI}^{+}\right)$: 168.1514, Found: 168.1511. Optical rotation: $[\alpha]_{\mathrm{D}}{ }^{20}+9.28\left(c=0.500, \mathrm{CHCl}_{3}\right)$ for a $54 \%$ ee sample.

Optical purity was determined by chiral GLC analysis in comparison with authentic racemic material (54\% ee sample below; conditions: $\beta$-dex column, $90{ }^{\circ} \mathrm{C}(300 \mathrm{~min}), 20{ }^{\circ} \mathrm{C} / \mathrm{min}$ to $140^{\circ} \mathrm{C}$ (10 $\mathrm{min}), 15 \mathrm{psi})$.
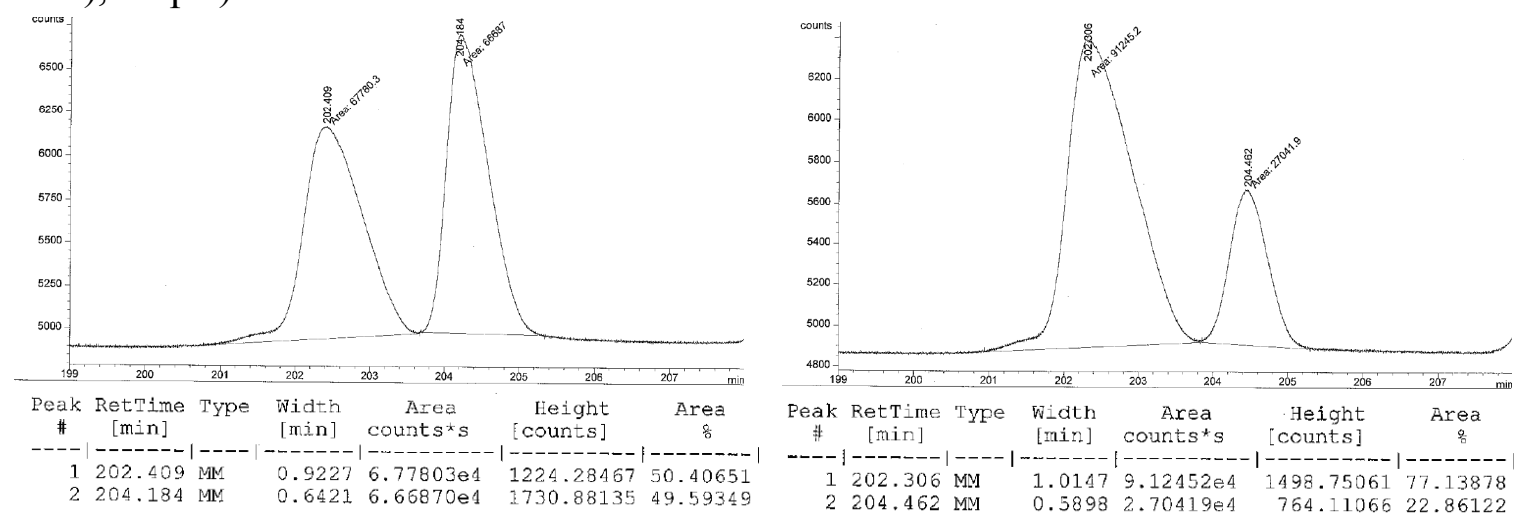

\section{Representative experimental procedure for $\mathrm{Cu}$-catalyzed conjugate addition of (aryl) $)_{2} \mathrm{Zn}$} reagents. An oven-dried 13×100 mm test tube was charged with chiral Ag complex 4 (5.6 mg, $0.0045 \mathrm{mmol}),(\mathrm{CuOTf})_{2} \cdot \mathrm{C}_{6} \mathrm{H}_{6}(2.7 \mathrm{mg}, 0.0045 \mathrm{mmol}), 3$-methyl-2-cyclohexenone (20 mg, 0.18 mmol), and $\mathrm{Ph}_{2} \mathrm{Zn}(120 \mathrm{mg}, 0.55 \mathrm{mmol})$, which were weighed out under a $\mathrm{N}_{2}$ atmosphere in a glove box (in the precise order mentioned above). The test tube was sealed with a septum and wrapped with parafilm. The reaction vessel was removed from the glove box. Diethyl ether (1.0 
$\mathrm{mL}$ ) was slowly added to the mixture in a dropwise manner (syringe) at $-78{ }^{\circ} \mathrm{C}$. After the addition of $\mathrm{Et}_{2} \mathrm{O}$, the solution was allowed to warm to $-30{ }^{\circ} \mathrm{C}$. After $48 \mathrm{~h}$ at $-30{ }^{\circ} \mathrm{C}$, the reaction was quenched by the addition of a saturated aqueous solution of ammonium chloride $(1.0 \mathrm{~mL})$ and then immediately $\mathrm{H}_{2} \mathrm{O}(1.0 \mathrm{~mL})$. The mixture was washed with $\mathrm{Et}_{2} \mathrm{O}(3 \times 1 \mathrm{~mL})$ and the combined organic layers were passed through a short plug of silica eluted with $\mathrm{Et}_{2} \mathrm{O}$. The volatiles were removed in vacuo and the resulting mixture was purified by silica gel column chromatography (hexanes/ $\left.\mathrm{Et}_{2} \mathrm{O}: 10 / 1\right)$ to afford $32.5 \mathrm{mg}(0.173 \mathrm{mmol}, 95.0 \%$ yield) of cyclic ketone $\mathbf{1 5}$ as colorless oil.

Important note: To ensure high efficiency and enantioselectivity, reactions must be set up in exactly the order described above.

(S)-3-Methyl-3-phenylcyclohexanone (15). IR (neat): 3087 (w), 3058 (w), 3024 (w), 3022 (w), 2962 (s), 2937 (s), 2870 (m), 2357 (w), 2332 (w), 1715 (s), 1602 (w) cm ${ }^{-1}$; ${ }^{1} \mathrm{H}$ NMR (400 MHz, $\left.\mathrm{CDCl}_{3}\right): \delta 7.35-7.30(4 \mathrm{H}, \mathrm{m}), 7.26-7.18(1 \mathrm{H}, \mathrm{m}), 2.89(1 \mathrm{H}, \mathrm{d}, J=14.4 \mathrm{~Hz}), 2.44(1 \mathrm{H}, \mathrm{d}, J=14.4$ $\mathrm{Hz}), 2.31(2 \mathrm{H}, \mathrm{t}, J=6.8 \mathrm{~Hz}), 2.22-2.16(1 \mathrm{H}, \mathrm{m}), 1.96-1.83(2 \mathrm{H}, \mathrm{m}), 1.72-1.61(1 \mathrm{H}, \mathrm{m}), 1.33(3 \mathrm{H}$, s); ${ }^{13} \mathrm{C} \mathrm{NMR} \mathrm{(100} \mathrm{MHz,} \mathrm{CDCl}_{3}$ ): $\delta 211.6,147.5,128.6,126.3,125.7,53.2,42.9,40.9$, 38.0, 29.9, 22.1; Anal Calcd for $\mathrm{C}_{13} \mathrm{H}_{16} \mathrm{O}$ : C, 82.94; H, 8.57; Found C, 82.67; H, 8.28; HRMS Calcd for $\mathrm{C}_{13} \mathrm{H}_{16} \mathrm{O}\left(\mathrm{EI}^{+}\right): 188.1201$, Found: 188.1199. Optical rotation: $[\alpha]_{\mathrm{D}}{ }^{20}+70.18\left(c=1.000, \mathrm{CHCl}_{3}\right)$ for a $97 \%$ ee sample.

Optical purity was determined by chiral GLC analysis in comparison with authentic racemic material (97\% ee sample below; conditions: CDGTA column, $95{ }^{\circ} \mathrm{C}(70 \mathrm{~min}), 0.5{ }^{\circ} \mathrm{C} / \mathrm{min}$ to $110^{\circ} \mathrm{C}(30 \mathrm{~min}), 20^{\circ} \mathrm{C} / \mathrm{min}$ to $\left.140^{\circ} \mathrm{C}(20 \mathrm{~min}), 15 \mathrm{psi}\right)$.
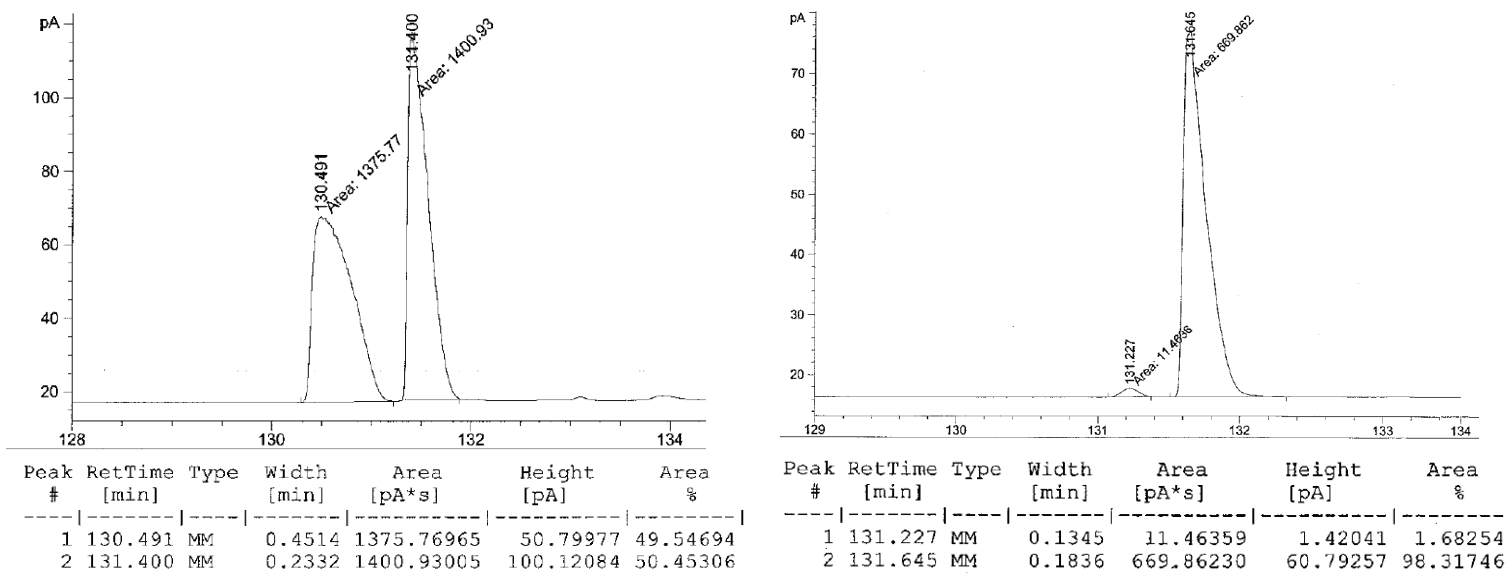

(S)-3-Ethyl-3-phenylcyclohexanone (10). IR (neat): 3089 (w), 3058 (w), 3031 (w), 3024 (w) 2962 (s), 2934 (s), 2877 (m), 2355 (w), 2332 (w), 1715 (s), 1601 (w), 1498 (m), 1460 (m), 1445 (s) $\mathrm{cm}^{-1} ;{ }^{1} \mathrm{H}$ NMR $\left(400 \mathrm{MHz}, \mathrm{CDCl}_{3}\right)$ : $\delta$ 7.32-7.27 (2H, m), 7.25-7.22 (2H, m), 7.20-7.15 (1H, m), $2.90(1 \mathrm{H}, \mathrm{d}, J=14.4 \mathrm{~Hz}), 2.40(1 \mathrm{H}, \mathrm{d}, J=14.4 \mathrm{~Hz}), 2.30-2.26(2 \mathrm{H}, \mathrm{m}), 2.19-2.13(1 \mathrm{H}, \mathrm{m}), 2.00-$ $1.93(1 \mathrm{H}, \mathrm{m}), 1.84-1.54(4 \mathrm{H}, \mathrm{m}), 0.58(3 \mathrm{H}, \mathrm{t}, J=7.6 \mathrm{~Hz}) ;{ }^{13} \mathrm{C} \mathrm{NMR}\left(100 \mathrm{MHz}, \mathrm{CDCl}_{3}\right): \delta 211.6$, 145.0, 128.6, 126.7, 126.2, 50.7, 46.6, 41.2, 36.4, 35.8, 21.7, 8.1; HRMS Calcd for $\mathrm{C}_{14} \mathrm{H}_{18} \mathrm{O}$ 
$\left(\mathrm{EI}^{+}\right)$: 202.1358, Found: 202.1362 . Optical rotation: $[\alpha]_{\mathrm{D}}{ }^{20}+63.77\left(c=1.000, \mathrm{CHCl}_{3}\right)$ for a $94 \%$ ee sample.

Optical purity was determined by chiral GLC analysis in comparison with authentic racemic material (94\% ee sample below; conditions: $\beta$-dex column, $140{ }^{\circ} \mathrm{C}, 15 \mathrm{psi}$ ).
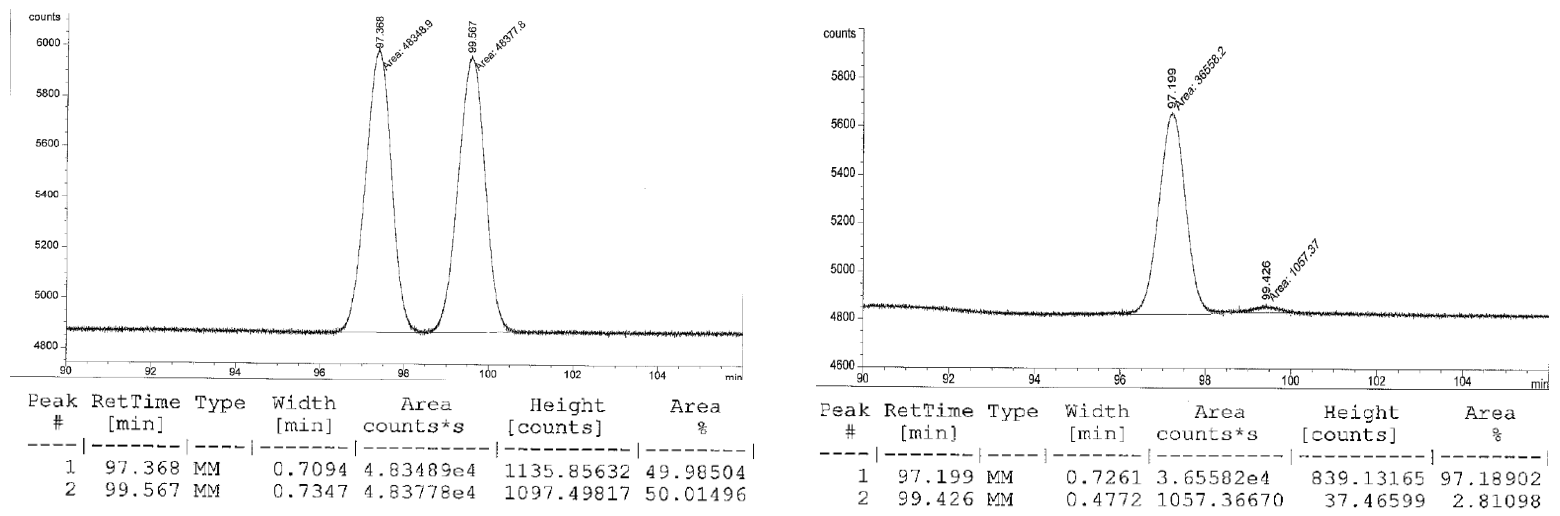

(S)-3-(4-pentenyl)-3-phenylcyclohexanone (16). IR (neat): 2936 (s), 2873 (m), 1709 (s), 1645 (m), 1438 (m), 1332 (m), 1242 (m), 996 (w), 918 (m), 762 (m), $711(\mathrm{~s}), 667$ (s) cm ${ }^{-1}$. ${ }^{1} \mathrm{H}$ NMR $\left(\mathrm{CDCl}_{3}, 400 \mathrm{MHz}\right): \delta$ 7.32-7.26 (2H, m), 7.25-7.22 (2H, m), 7.20-7.15 (1H, m), 5.63 (1H, dddd, $J=17.2,10.4,6.8,6.8 \mathrm{~Hz}), 4.91-4.85(2 \mathrm{H}, \mathrm{m}), 2.91(1 \mathrm{H}, \mathrm{d}, J=14.0 \mathrm{~Hz}), 2.42(1 \mathrm{H}, \mathrm{d}, J=14.0$ $\mathrm{Hz}), 2.26-2.26(2 \mathrm{H}, \mathrm{m}), 2.19-2.00(1 \mathrm{H}, \mathrm{m}), 2.00-1.51(7 \mathrm{H}, \mathrm{m}), 1.20-1.09(1 \mathrm{H}, \mathrm{m}), 0.99-0.88(1 \mathrm{H}$, m). ${ }^{13} \mathrm{C} \mathrm{NMR}\left(\mathrm{CDCl}_{3}, 100 \mathrm{MHz}\right): \delta 211.7,145.3,138.6,128.7,126.6,126.3,114.9,51.3,46.3$, 42.8, 41.2, 36.8, 34.1, 22.9, 21.7. HRMS calcd for $\mathrm{C}_{17} \mathrm{H}_{22} \mathrm{O}: 242.1671$, Found: 242.1676. Optical rotation: $[\alpha]_{\mathrm{D}}^{20}+45.17\left(c=1.970, \mathrm{CHCl}_{3}\right)$ for an $89 \%$ ee sample.

Optical purity was determined by chiral GLC analysis in comparison with authentic racemic material (89\% ee sample below; conditions: $\beta$-dex column, $120{ }^{\circ} \mathrm{C}, 15 \mathrm{psi}$ ).
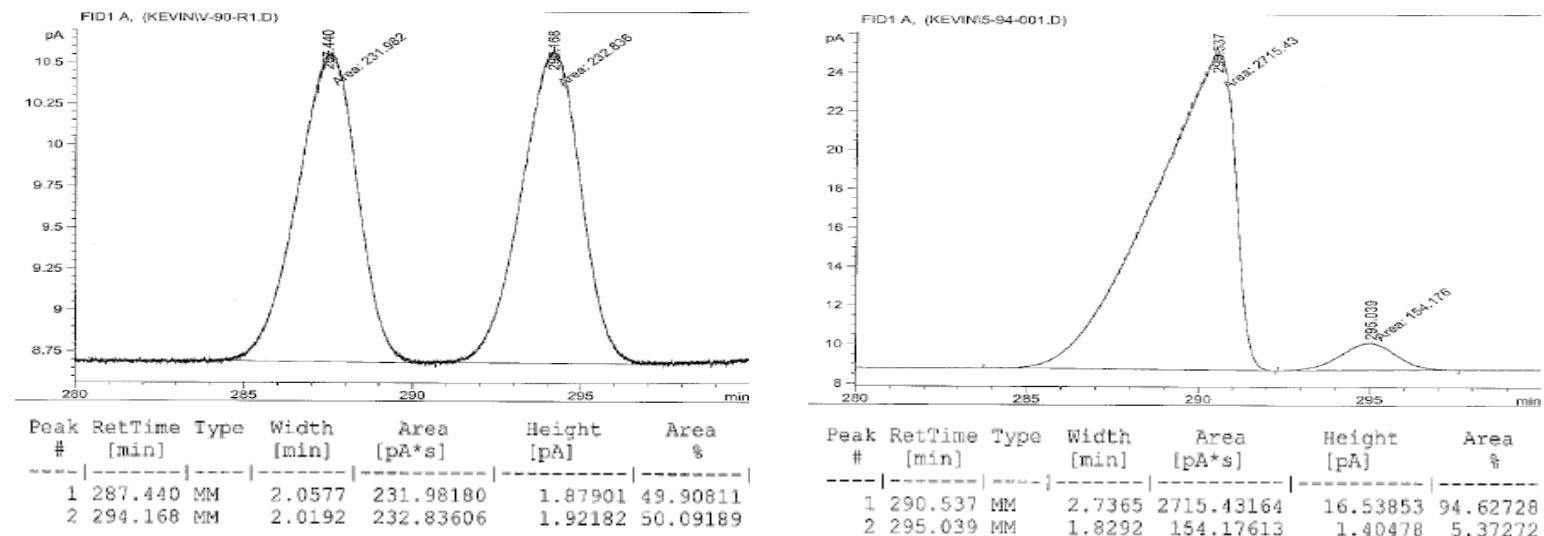

(S)-3-(4-methoxyphenyl)-3-methylcyclohexanone (17). The general procedure described on page 7 was followed, except that toluene was used as the solvent. IR (neat): 2964 (s), 2880 (m), 1712 (s), 1611 (m), 1516 (s), 1455 (m), 1309 (m), 1259 (s), 1186 (m), 1041 (m), 840 (m) cm ${ }^{-1}$. ${ }^{1} \mathrm{H} \mathrm{NMR}\left(\mathrm{CDCl}_{3}, 400 \mathrm{MHz}\right): \delta 7.21(2 \mathrm{H}, \mathrm{dt}, J=5.6,3.6 \mathrm{~Hz}), 6.84(2 \mathrm{H}, \mathrm{dt}, J=5.6,3.6 \mathrm{~Hz}), 3.37$ $(3 \mathrm{H}, \mathrm{s}), 2.83(1 \mathrm{H}, \mathrm{d}, J=14.4 \mathrm{~Hz}), 2.40(1 \mathrm{H}, \mathrm{d}, J=14.4 \mathrm{~Hz}), 2.85(2 \mathrm{H}, \mathrm{t}, J=6.8 \mathrm{~Hz}), 2.17-2.11$ 
$(1 \mathrm{H}, \mathrm{m}), 1.91-1.80(2 \mathrm{H}, \mathrm{m}), 1.69-1.59(1 \mathrm{H}, \mathrm{m}), 1.28(3 \mathrm{H}, \mathrm{s}) .{ }^{13} \mathrm{C} \mathrm{NMR}\left(\mathrm{CDCl}_{3}, 100 \mathrm{MHz}\right)$ : $\delta$ 200.7, 158.0, 139.7, 126.9, 114.0, 55.4, 53.5, 42.5, 41.5, 38.3, 30.3, 22.2. HRMS calcd for $\mathrm{C}_{14} \mathrm{H}_{18} \mathrm{O}: 218.1307$, Found: 218.1298. Optical Rotation: $[\alpha]_{\mathrm{D}}^{20}+51.71\left(c=0.960, \mathrm{CHCl}_{3}\right)$ for a $90 \%$ ee sample.

Optical purity was determined by chiral HPLC analysis in comparison with authentic racemic material (90\% sample below; conditions: chiralpak AS column $(25 \mathrm{~cm} \times 0.46 \mathrm{~cm}), 95 / 5$ hexanes $/ i-\mathrm{PrOH}, 1.0 \mathrm{~mL} / \mathrm{min}, 254 \mathrm{~nm})$.
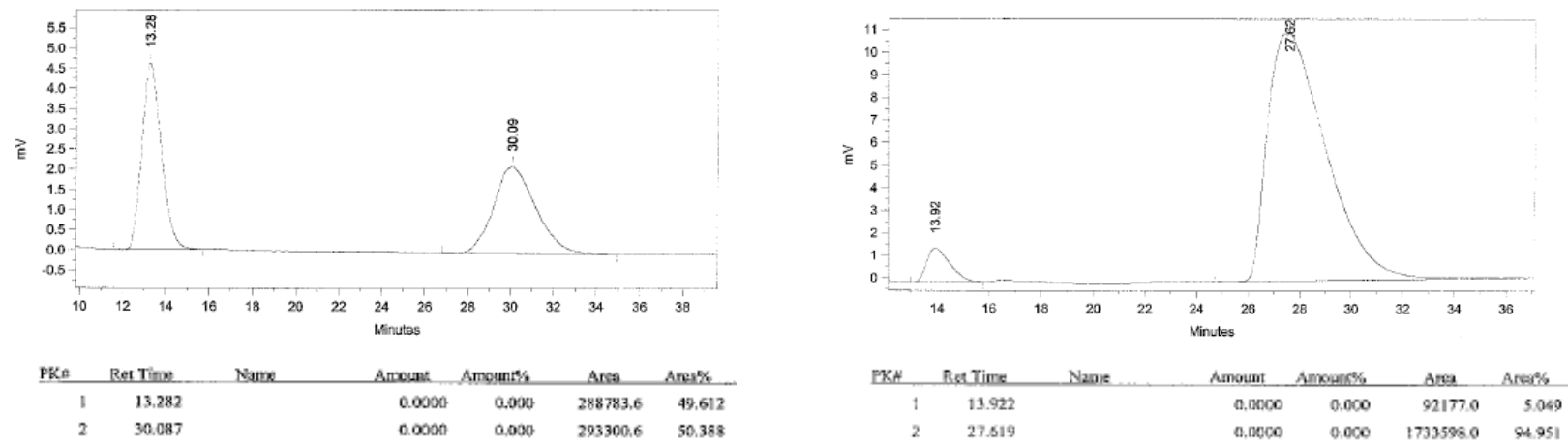

(S)-3-Methyl-3-phenylcycloheptanone (18). IR (neat): 3088 (w), 3056 (m), 3032 (m), 3022 (m) $2931(\mathrm{~s}), 2862(\mathrm{~s}), 1949(\mathrm{w}), 1877(\mathrm{w}), 1805(\mathrm{w}), 1696(\mathrm{~s}), 1599(\mathrm{~m}), 1497$ (s), 1460 (s), $1444(\mathrm{~s}) \mathrm{cm}^{-1} ;{ }^{1} \mathrm{H}$ NMR $\left(400 \mathrm{MHz}, \mathrm{CDCl}_{3}\right): \delta$ 7.33-7.30 $(4 \mathrm{H}, \mathrm{m}), 7.22-7.17(1 \mathrm{H}, \mathrm{m}), 3.21(1 \mathrm{H}, \mathrm{d}$, $J=14.4,1.2 \mathrm{~Hz}), 2.71(1 \mathrm{H}, \mathrm{d}, J=14.4 \mathrm{~Hz}), 2.46-2.36(2 \mathrm{H}, \mathrm{m}), 2.23-2.15(1 \mathrm{H}, \mathrm{m}), 1.84-1.70(5 \mathrm{H}$, m), $1.27(3 \mathrm{H}, \mathrm{s}) ;{ }^{13} \mathrm{C} \mathrm{NMR}\left(100 \mathrm{MHz}, \mathrm{CDCl}_{3}\right): \delta 213.9,148.0,128.7,126.1,125.7,55.8,44.3$, 43.6, 39.9, 32.0, 25.9, 24.0. Anal Calcd for $\mathrm{C}_{14} \mathrm{H}_{18} \mathrm{O}: \mathrm{C}, 83.12$; H, 8.97; Found C, 82.92; H, 9.11; HRMS Calcd for $\mathrm{C}_{14} \mathrm{H}_{18} \mathrm{O}\left(\mathrm{EI}^{+}\right)$: 202.1358 , Found: 202.1359. Optical rotation: $[\alpha]_{\mathrm{D}}^{20}+74.78$ $\left(c=1.000, \mathrm{CHCl}_{3}\right)$ for a $96 \%$ ee sample.

Optical purity was determined by chiral GLC analysis in comparison with authentic racemic material ( $96 \%$ ee sample below; conditions: $\alpha$-dex column, $140{ }^{\circ} \mathrm{C}, 15 \mathrm{psi}$ ).
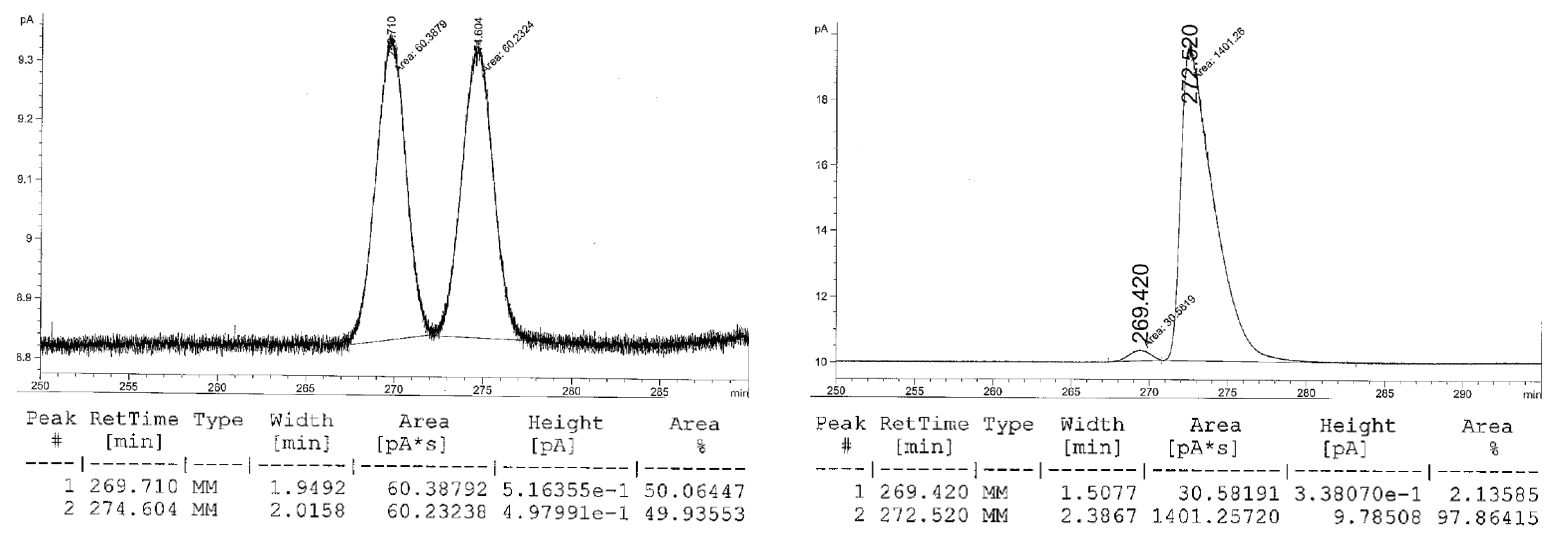

\section{Representative experimental procedure for direct synthesis of enolsilanes}


((S)-3-Methyl-3-phenylcyclohex-1-enyloxy)trimethylsilane (19). An oven-dried $13 \times 100 \mathrm{~mm}$ test tube charged with Ag complex $4(5.6 \mathrm{mg}, 0.0045 \mathrm{mmol}),(\mathrm{CuOTf}){ }_{2} \cdot \mathrm{C}_{6} \mathrm{H}_{6}(2.7 \mathrm{mg}, 0.0045$ $\mathrm{mmol}$ ), 3-methyl-2-cyclohexenone (20 mg, $0.18 \mathrm{mmol})$, and $\mathrm{Ph}_{2} \mathrm{Zn}(120 \mathrm{mg}, 0.546 \mathrm{mmol})$, which were weighed out under $\mathrm{N}_{2}$ atmosphere in a glove box. The reaction vessel was sealed with a septum and wrapped with parafilm before being removed from the glove box. Diethyl ether $(1.0 \mathrm{~mL})$ was slowly added at $-78{ }^{\circ} \mathrm{C}$ (syringe). After the addition of $\mathrm{Et}_{2} \mathrm{O}$, the solution was allowed to warm to $-30{ }^{\circ} \mathrm{C}$. After $48 \mathrm{~h}$ at $-30^{\circ} \mathrm{C}$, the reaction was cooled to $-78{ }^{\circ} \mathrm{C}$ and TMSOTf ( $99 \mu \mathrm{L}, 0.55 \mathrm{mmol}$ ) was added (syringe). After the addition of TMSOTf, the mixture was allowed to warm to $22{ }^{\circ} \mathrm{C}$ and stir for $1 \mathrm{~h}$. The reaction was quenched through addition of a saturated solution of aqueous $\mathrm{NaHCO}_{3}(1.0 \mathrm{~mL})$, and the mixture was washed with $\mathrm{Et}_{2} \mathrm{O}(3 \mathrm{x} 1$ $\mathrm{mL}$ ). The volatiles were removed in vacuo and the resulting dark brown oil was purified by silica gel column chromatography (hexanes/ $\left.\mathrm{Et}_{2} \mathrm{O}: 20 / 1\right)$ to afford $46.8 \mathrm{mg}(0.180 \mathrm{mmol},>98 \%$ yield) of $\mathbf{1 9}$ as a colorless oil. (Note: Before the mixture was added, the silica gel column was eluted with $0.5 \mathrm{~mL}$ of $\mathrm{Et}_{3} \mathrm{~N}$.) IR (neat): 3081 (w), 3057 (w), 3029 (w), 3020 (w), 2959 (s), 2934 (s), 2867 (w), 2853 (w), 2836 (w), 1665 (s), 1251 (s), 1195 (s), 895 (s), 865 (s), 847 (s), 760 (s), 697 (s) $\mathrm{cm}^{-1} ;{ }^{1} \mathrm{H}$ NMR $\left(400 \mathrm{MHz}, \mathrm{CDCl}_{3}\right):$ 8 7.43-7.31 $(4 \mathrm{H}, \mathrm{m}), 7.22-7.18(1 \mathrm{H}, \mathrm{m}), 4.99-4.98(1 \mathrm{H}, \mathrm{m})$, 2.09-2.05 (2H, m), 1.87-1.82 (1H, m), 1.68-1.60 (2H, m), 1.52-1.44 (1H, m), $1.43(3 \mathrm{H}, \mathrm{s}), 0.28$ $(9 \mathrm{H}, \mathrm{s}) ;{ }^{13} \mathrm{C}$ NMR $\left(100 \mathrm{MHz}, \mathrm{CDCl}_{3}\right): \delta 150.7,141.4,128.0,126.8,125.7,113.5,40.1,39.0,30.3$, 30.0, 19.7, 0.6. HRMS Calcd for $\mathrm{C}_{16} \mathrm{H}_{24} \mathrm{OSi}\left(\mathrm{EI}^{+}\right)$: 260.1596, Found: 260.1600 .

$((\boldsymbol{R})$-3-Ethyl-3-methylcyclohex-1-enyloxy)trimethylsilane. Note: This is additional data; this compound does not appear in the body of the text. $>98 \%$ conv, $>98 \%$ yield, $93 \%$ ee. IR (neat): 2962 (s), 2933 (s), 2878 (w), 2871 (w), 2851 (w), 1665 (m), 1262 (m), 1250 (s), 1203 (s), 1138 (s), $900(\mathrm{~s}), 867$ (s), $842(\mathrm{~s}) \mathrm{cm}^{-1} ;{ }^{1} \mathrm{H}$ NMR $\left(400 \mathrm{MHz}, \mathrm{CDCl}_{3}\right): \delta 4.64(1 \mathrm{H}, \mathrm{s}), 1.95-1.92(2 \mathrm{H}, \mathrm{m})$, 1.69-1.63 (2H, m), 1.41-1.21 (4H, m), $0.92(3 \mathrm{H}, \mathrm{s}), 0.82(3 \mathrm{H}, \mathrm{t}, J=7.6 \mathrm{~Hz}), 0.17(9 \mathrm{H}, \mathrm{s}) ;{ }^{13} \mathrm{C}$ NMR $\left(100 \mathrm{MHz}, \mathrm{CDCl}_{3}\right): \delta 149.4,114.7,35.8,34.8,34.3,30.1,27.6,19.8,8.7,0.5$. HRMS Calcd for $\mathrm{C}_{12} \mathrm{H}_{24} \mathrm{OSi}\left(\mathrm{EI}^{+}, \mathrm{M}-\mathrm{H}\right): 211.1518$, Found: 211.1512.

\section{- Representative experimental procedure for synthesis of enolsilanes through deprotonation/trap of ACA products}

((S)-5-Methyl-5-phenylcyclohex-1-enyloxy)trimethylsilane (20). A solution of $n$-BuLi (345 $\mu \mathrm{L}, 0.517 \mathrm{mmol}, 1.5 \mathrm{M}$ in hexanes) was added to a cold $\left(-78^{\circ} \mathrm{C}\right) \mathrm{THF}(2.0 \mathrm{~mL})$ solution of 2,2,6,6-tetramethyl piperidine ( $99 \mu \mathrm{L}, 0.59 \mathrm{mmol}$ ). The mixture was allowed to warm to $22{ }^{\circ} \mathrm{C}$, stirred for $5 \mathrm{~min}$, and cooled again to $-78{ }^{\circ} \mathrm{C}$. Optically enriched ketone 15 ( $65 \mathrm{mg}, 0.34 \mathrm{mmol}$ ), dissolved in THF $(1 \mathrm{~mL})$, was added to the mixture, which was allowed to stir for $30 \mathrm{~min}$ at $78^{\circ} \mathrm{C}$. Trimethylsilyltriflate $(187 \mu \mathrm{L}, 1.03 \mathrm{mmol})$ was added and the mixture was allowed to stir for an additional $15 \mathrm{~min}$ at $-78^{\circ} \mathrm{C}$. A saturated solution of $\mathrm{NaHCO}_{3}(1.0 \mathrm{~mL})$ was added and the mixture was allowed to warm slowly to $22{ }^{\circ} \mathrm{C}$, at which time the solution was diluted through addition of $\mathrm{H}_{2} \mathrm{O}(1 \mathrm{ml})$. The mixture was washed with $\mathrm{Et}_{2} \mathrm{O}(3 \times 1.0 \mathrm{~mL})$ and the combined 
organic layers were concentrated in vacuo. The resulting light yellow oil purified by silica gel column chromatography (hexanes/ $\left.\mathrm{Et}_{2} \mathrm{O}: 20 / 1\right)$ to afford $86 \mathrm{mg}(0.33 \mathrm{mmol}, 96 \%$ yield) of enolsilane $\mathbf{2 0}$ as a colorless oil. (Note: Before the mixture was added, the silica gel column was eluted with $0.5 \mathrm{~mL}$ of $\mathrm{Et}_{3} \mathrm{~N}$.) IR (neat): 3087 (w), 3056 (w), 3030 (w), 3024 (w), 2962 (s), 2924 (s), 2848 (m), 1671 (s), 1496 (m), 1443 (m), 1357 (m), 1251 (s), 1211 (s), 1186 (s), 1172 (s), 912 (s), 884 (s), 847 (s), 761 (s), 698 (s) cm ${ }^{-1} ;{ }^{1} \mathrm{H} \mathrm{NMR} \mathrm{(400} \mathrm{MHz,} \mathrm{CDCl}{ }_{3}$ ): $\delta$ 7.43-7.30 (4H, m), 7.24-7.19 (1H, m), 4.88-4.86 (1H, m), $2.51(1 \mathrm{H}, \mathrm{d}, J=16.4 \mathrm{~Hz}), 2.15(1 \mathrm{H}, \mathrm{d}, J=16.8 \mathrm{~Hz}), 2.11-$ $2.05(1 \mathrm{H}, \mathrm{m}), 1.93-1.81(2 \mathrm{H}, \mathrm{m}), 1.75-1.68(1 \mathrm{H}, \mathrm{m}), 1.32(3 \mathrm{H}, \mathrm{s}), 0.25(9 \mathrm{H}, \mathrm{s}) ;{ }^{13} \mathrm{C}$ NMR $(100$ $\left.\mathrm{MHz}, \mathrm{CDCl}_{3}\right): \delta 149.4,127.3,128.1,125.9,125.8,103.3,42.4,37.9,34.7,28.3,21.7,0.7$. HRMS Calcd for $\mathrm{C}_{16} \mathrm{H}_{24} \mathrm{OSi}\left(\mathrm{EI}^{+}\right): 260.1596$, Found: 260.1594 .

((R)-6-Methyl-6-phenylcyclohept-1-enyloxy)trimethylsilane. Note: This is additional data; this compound does not appear in the body of the text. IR (neat): $31091(\mathrm{~m}), 3090(\mathrm{~m}), 3057(\mathrm{w})$, 3026 (w), 3010 (w), 2958 (s), 2929 (s), 2878 (m), 2860 (m), 1660 (m), 1458 (m), 1455 (m), 1444 (m), 1382 (m), 1296 (m), 1250 (s), 1228 (s), 1193 (m), 886 (s), 840 (s) cm ${ }^{-1} ;{ }^{1} \mathrm{H}$ NMR (400 MHz, $\left.\mathrm{CDCl}_{3}\right): \delta 7.44-7.42(2 \mathrm{H}, \mathrm{m}), 7.33-7.28(2 \mathrm{H}, \mathrm{m}), 7.19-7.15(1 \mathrm{H}, \mathrm{m}), 4.94(1 \mathrm{H}, \mathrm{t}, J=6.8 \mathrm{~Hz})$, $2.85(1 \mathrm{H}, \mathrm{d}, J=14.8 \mathrm{~Hz}), 2.41(1 \mathrm{H}, \mathrm{d}, J=14.8 \mathrm{~Hz}), 2.26-2.19(1 \mathrm{H}, \mathrm{m}), 2.05-1.99(2 \mathrm{H}, \mathrm{m}), 1.78-$ $1.47(3 \mathrm{H}, \mathrm{m}), 1.30(3 \mathrm{H}, \mathrm{s}), 0.13(9 \mathrm{H}, \mathrm{s}) ;{ }^{13} \mathrm{C} \mathrm{NMR}\left(100 \mathrm{MHz}, \mathrm{CDCl}_{3}\right): \delta 153.1,149.9,128.2$, 126.2, 125.5, 107.1, 47.2, 45.2, 38.3, 29.4, 26.0, 23.8, 0.4; HRMS Calcd for $\mathrm{C}_{17} \mathrm{H}_{26} \mathrm{OSi}\left(\mathrm{EI}^{+}\right)$: 274.1753, Found: 274.1755.

- Representative procedure for direct synthesis of enoltriflate 21: An oven-dried 13x100 mm test tube charged with chiral Ag complex 4 (3.1 mg, $0.0050 \mathrm{mmol}),(\mathrm{CuOTf}){ }_{2}{ }^{\circ} \mathrm{C}_{6} \mathrm{H}_{6}(1.3 \mathrm{mg}$, $0.0025 \mathrm{mmol})$, and 3-methyl-2-cyclohexenone $(10.0 \mathrm{mg}, 0.100 \mathrm{mmol})$. All the above were weighed out under an $\mathrm{N}_{2}$ atmosphere in a glove box. The test tube was sealed with a septum and wrapped with parafilm before the tube was removed from the glove box. Diethyl ether $(750 \mu \mathrm{L})$ was added at $22{ }^{\circ} \mathrm{C}$; the resulting solution was allowed to stir for $10 \mathrm{~min}$. Diethylzinc $(30 \mu \mathrm{L}$, $0.30 \mathrm{mmol}$ ) was added dropwise to the mixture after it was cooled to $-78{ }^{\circ} \mathrm{C}$; during the addition of $\mathrm{Et}_{2} \mathrm{Zn}$ the mixture turned dark brown. After addition of diethylzinc, the mixture was allowed to warm to $-30{ }^{\circ} \mathrm{C}$. After $6 \mathrm{~h}$ at $-30^{\circ} \mathrm{C}, \mathrm{Tf}_{2} \mathrm{O}(168 \mathrm{~mL}, 1.0 \mathrm{mmol})$ was added to the mixture by a syringe. The mixture was immediately allowed to warm to $22^{\circ} \mathrm{C}$ and stir for $1 \mathrm{~h}$. The reaction was quenched by the addition of a saturated solution of aqueous sodium bicarbonate $(1 \mathrm{~mL})$ and $\mathrm{H}_{2} \mathrm{O}(1 \mathrm{~mL})$. The mixture was washed with petroleum ether $(3 \times 1 \mathrm{~mL})$, and the combined organic layers were passed through a short plug $(4 \mathrm{~cm} \mathrm{x} 1 \mathrm{~cm})$ of silica gel eluted with petroleum ether to afford $27.0 \mathrm{mg}(0.0992 \mathrm{mmol}, 99.2 \%$ yield $)$ of $\mathbf{2 2}$ as a colorless oil. Important note: To ensure high efficiency and enantioselectivity, reactions must be set up in exactly the order described above. The optical purity of the sample was obtained by treatment of the enoltriflate with MeLi to afford enantiomerically enriched cyclic ketone $\mathbf{6}$. 
(R)-3-Ethyl-3-methylcyclohex-1-enyl trifluoromethanesulfonate (21). IR (neat): 2966 (m), 2933 (m), 2856 (w), 1416 (s), 1257 (m), 1213 (s), 1153 (s), 1026 (w), 960 (w), 894 (w), 845 (w), $801(\mathrm{w}) \mathrm{cm}^{-1} ;{ }^{1} \mathrm{H}$ NMR (400 MHz, $\mathrm{CDCl}_{3}$ ): $\delta 5.49(1 \mathrm{H}, \mathrm{s}), 2.32-2.19(2 \mathrm{H}, \mathrm{m}), 1.84-1.70(2 \mathrm{H}, \mathrm{m})$, 1.50-1.30 (4H, m), $1.00(3 \mathrm{H}, \mathrm{s}), 0.83(3 \mathrm{H}, \mathrm{t}, J=7.2 \mathrm{~Hz}) ;{ }^{13} \mathrm{C} \mathrm{NMR}\left(100 \mathrm{MHz}, \mathrm{CDCl}_{3}\right): \delta 148.7$, 127.2, $118.7(\mathrm{q}, J=318.8 \mathrm{~Hz}), 36.2,34.8,33.8,27.8,26.4,19.7,8.4$.

(R)-(3-Ethyl-3-methylcyclohex-1-enyl)benzene (22). An oven-dried vial was charged with $\mathrm{Pd}(\mathrm{OAc})_{2}(1.0 \mathrm{mg}, 0.0044 \mathrm{mmol}), \mathrm{PPh}_{3}(2.5 \mathrm{mg}, 0.0097 \mathrm{mmol})$, and $\mathrm{PhB}(\mathrm{OH})_{2}(6.7 \mathrm{mg}, 0.055$ mmol) was weighed out under an $\mathrm{N}_{2}$ atmosphere in a glovebox. The vial was sealed with a septum prior to removal from the glovebox. In a separate vial, enol triflate $21(12.2 \mathrm{mg}, 0.0448$ mmol) dissolved in anhydrous THF $(1.0 \mathrm{~mL})$ was added to the vial containing $\mathrm{Pd}(\mathrm{OAc})_{2}, \mathrm{PPh}_{3}$, and $\mathrm{PhB}(\mathrm{OH})_{2}$ through a syringe. The mixture was stirred for $10 \mathrm{~min}$ at $22{ }^{\circ} \mathrm{C}$ after which time aqueous $\mathrm{KOH}(0.5 \mathrm{M}, 88 \mu \mathrm{L}, 0.044 \mathrm{mmol})$ was added via syringe. After $45 \mathrm{~min}$ at $22{ }^{\circ} \mathrm{C}$ the reaction was quenched with $\mathrm{H}_{2} \mathrm{O}(1 \mathrm{~mL})$ and extracted with EtOAc $(4 \times 1 \mathrm{~mL})$. The combined organic extracts were dried with $\mathrm{MgSO}_{4}$, filtered and concentrated to yield a dark brown oil, which was purified by silica gel column chromatography to afford $6.8 \mathrm{mg}(0.033,77 \%)$ of 22 as a colorless oil. IR (neat): 3029 (w), 2963 (s), 2936 (s), 2864 (m), 1607 (w), 1496 (w), 1447 (m), 1375 (m), 1006 (w), 879 (w), 768 (s), 697 (s) cm ${ }^{-1} ;{ }^{1} \mathrm{H}$ NMR (400 MHz, CDCl $)_{3}$ : $\delta$ 7.40-7.37 (2H, $\mathrm{m}), 7.32-7.27(2 \mathrm{H}, \mathrm{m}), 7.21(1 \mathrm{H}, \mathrm{tt}, J=7.2,1.6 \mathrm{~Hz}), 5.81(1 \mathrm{H}, \mathrm{s}), 2.41-2.82(2 \mathrm{H}, \mathrm{m}), 1.83-1.70$ $(2 \mathrm{H}, \mathrm{m}), 1.57-1.50(1 \mathrm{H}, \mathrm{m}), 1.44-1.35(3 \mathrm{H}, \mathrm{m}), 1.01(3 \mathrm{H}, \mathrm{s}), 0.87(3 \mathrm{H}, \mathrm{t}, J=7.6 \mathrm{~Hz}) ;{ }^{13} \mathrm{C} \mathrm{NMR}$ $\left(100 \mathrm{MHz}, \mathrm{CDCl}_{3}\right): \delta 142.9,135.2,134.5,128.3,126.7,125.3,35.4,35.2,33.9,27.8,27.0,20.0$, 8.6. Optical Rotation: $[\alpha]_{\mathrm{D}}{ }^{20}-20.4\left(c=0.453, \mathrm{CHCl}_{3}\right)$ for an $87 \%$ ee sample.

- Proof of absolute stereochemistry. The following sequence was carried out in order to obtain optically enriched material (c).

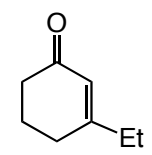

a

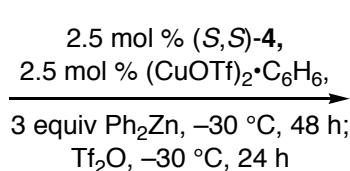

$\mathrm{Tf}_{2} \mathrm{O},-30^{\circ} \mathrm{C}, 24 \mathrm{~h}$
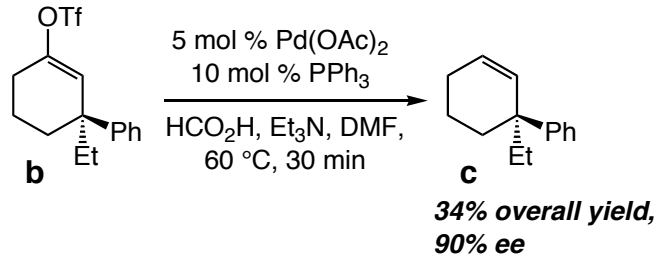

An oven-dried 13x100 mm test tube was charged with Ag complex 4 (4.9 mg, $0.0081 \mathrm{mmol}$ ), $(\mathrm{CuOTf})_{2} \bullet \mathrm{C}_{6} \mathrm{H}_{6}(2.0 \mathrm{mg}, 0.0045 \mathrm{mmol})$, 3-ethyl-2-cyclohexenone $(19.9 \mathrm{mg}, 0.161 \mathrm{mmol})$ and diphenylzinc (106 $\mathrm{mg}, 0.483 \mathrm{mmol}$ ), weighed out under $\mathrm{N}_{2}$ atmosphere (in the above specific order). The tube was sealed with a septum, wrapped with parafilm. Diethyl ether $(1.0 \mathrm{~mL})$ was added in a dropwise manner (syringe) at $-78^{\circ} \mathrm{C}$. After the addition of diethyl ether the mixture was allowed to warm to $-30^{\circ} \mathrm{C}$. After $48 \mathrm{~h}$ at $-30^{\circ} \mathrm{C}, \mathrm{Tf}_{2} \mathrm{O}(142 \mu \mathrm{L}, 0.850 \mathrm{mmol})$ was added at $-30{ }^{\circ} \mathrm{C}$ through the septum by a syringe and the mixture was kept at $-30{ }^{\circ} \mathrm{C}$ for $24 \mathrm{~h}$. The reaction was quenched through addition of a saturated solution of aqueous $\mathrm{NaHCO}_{3}(1.0 \mathrm{~mL})$, followed by $\mathrm{H}_{2} \mathrm{O}(1.0 \mathrm{~mL})$. The resulting mixture was washed with $\mathrm{Et}_{2} \mathrm{O}(3 \times 1.0 \mathrm{~mL})$ and passed 
through a short plug of silica gel eluted with $\mathrm{Et}_{2} \mathrm{O}$. The volatiles were removed in vacuo and the resulting colorless oil was purified by silica gel chromatography (100\% hexanes) to afford 25.5 $\mathrm{mg}(0.08 \mathrm{mmol}, 42 \%$ yield $)$ of enoltriflate $\mathbf{b}$ as colorless oil. Important note: To ensure high efficiency and enantioselectivity the reaction must be set up in exactly the order described above. IR (neat): 2973 (w), 2938 (w), 1688 (w), 1422 (s), 1252 (m), 1222 (s), 1146 (s), 1016 (w), 906 (m), $876(\mathrm{w}), 845(\mathrm{w}), 765(\mathrm{w}), 710(\mathrm{w}), 620(\mathrm{w}) \mathrm{cm}^{-1} ;{ }^{1} \mathrm{H}$ NMR (400 MHz, $\left.\mathrm{CDCl}_{3}\right): \delta$ 7.34-7.29 $(2 \mathrm{H}, \mathrm{m}), 7.25-7.18(3 \mathrm{H}, \mathrm{m}), 5.96(1 \mathrm{H}, \mathrm{s}), 2.42-2.25(2 \mathrm{H}, \mathrm{m}), 1.95-1.85(2 \mathrm{H}, \mathrm{m}), 1.80-1.65(3 \mathrm{H}$, $\mathrm{m}), 1.54-1.43(1 \mathrm{H}, \mathrm{m}), 0.75(3 \mathrm{H}, \mathrm{t}, J=7.2 \mathrm{~Hz}) ;{ }^{13} \mathrm{C} \mathrm{NMR}\left(100 \mathrm{MHz}, \mathrm{CDCl}_{3}\right): \delta 150.3,146.1$, 128.6, 127.0, 126.4, 124.3, 118.8 (q, $J=318.1 \mathrm{~Hz}), 45.0,35.9,34.7,28.0$, 19.3, 8.7. HRMS Calcd for $\mathrm{C}_{15} \mathrm{H}_{17} \mathrm{O}_{3} \mathrm{~F}_{3} \mathrm{~S}\left(\mathrm{EI}^{+}\right)$: 334.0851, Found: 334.0848 .

1-((S)-1-Methylcyclohex-2-enyl)benzene (c). An oven-dried vial was charged with $\mathrm{Pd}(\mathrm{OAc})_{2}$ (0.98 mg, $0.0044 \mathrm{mmol}$ ) and $\mathrm{PPh}_{3}\left(2.3 \mathrm{mg}, 0.0088 \mathrm{mmol}\right.$ ), was weighed out under $\mathrm{N}_{2}$ atmosphere. The vial was sealed with a septum before it was removed from the govebox. In a separate flask, enol triflate $22(21 \mathrm{mg}, 0.089 \mathrm{mmol})$ dissolved in anhydrous DMF (1.0 mL) was added through a syringe to the vial containing $\mathrm{Pd}(\mathrm{OAc})_{2}$ and $\mathrm{PPh}_{3}$. The mixture was charged with $\mathrm{Et}_{3} \mathrm{~N}(37.0 \mu \mathrm{L}, 0.267 \mathrm{mmol})$, followed by formic acid $(6.8 \mu \mathrm{L}, 0.18 \mathrm{mmol})$, and was heated to $60{ }^{\circ} \mathrm{C}$ for $30 \mathrm{~min}$, during which time the solution turned black. The mixture was cooled to $22{ }^{\circ} \mathrm{C}$ and diluted by the addition of $\mathrm{H}_{2} \mathrm{O}(1.0 \mathrm{~mL})$, followed by washing with petroleum ether $(5 \times 1.0 \mathrm{~mL})$. The combined organic layers were passed through a short plug of silica gel eluted with petroleum ether. The filtrate was concentrated under reduced pressure to yield $\mathbf{2 3}$ as a colorless oil (11.5 mg, $0.0167 \mathrm{mmol}, 69.5 \%$ yield). IR (neat): 3065 (w), 3029 (w), 2981 (m), 2934 (s), 2874 (m), 2832 (w), 1499 (m), 1451 (m), 1374 (w), 1047 (w), 939 (w), 916 (w), 773 (s), 737 (m), 713 (s), $582(\mathrm{w}) \mathrm{cm}^{-1} ;{ }^{1} \mathrm{H} \mathrm{NMR}\left(400 \mathrm{MHz}, \mathrm{CDCl}_{3}\right): \delta$ 7.32-7.25 (4H, m), 7.17-7.12 (1H, $\mathrm{m}), 5.91-5.82(2 \mathrm{H}, \mathrm{m}), 2.01-1.97(2 \mathrm{H}, \mathrm{m}), 1.90-1.64(4 \mathrm{H}, \mathrm{m}), 1.58-1.50(1 \mathrm{H}, \mathrm{m}), 1.38-1.27(1 \mathrm{H}$, $\mathrm{m}), 0.73(3 \mathrm{H}, \mathrm{t}, J=7.2 \mathrm{~Hz}) ;{ }^{13} \mathrm{C} \mathrm{NMR}\left(100 \mathrm{MHz}, \mathrm{CDCl}_{3}\right): \delta 148.4,133.0,128.0,127.9,127.3$, 125.5, 43.1, 36.8, 35.1, 25.7, 19.1, 8.8. HRMS Calcd for $\mathrm{C}_{14} \mathrm{H}_{18}\left(\mathrm{EI}^{+}\right)$: 186.1409, Found: 186.1404; Optical Rotation: $[\alpha]_{\mathrm{D}}{ }^{20}-27.17\left(c=0.780, \mathrm{CHCl}_{3}\right)$ for a $40 \%$ ee sample.

The optical rotation of cyclic alkene c was compared to a value reported previously by Breit, who assigned (+) rotation to the $R$ enantiomer, but did not provide an exact value. ${ }^{6}$

- Preparation of di-4-methoxyphenyl zinc. Mg turnings (1.8 g, $75 \mathrm{mmol})$ were weighed out into a two-neck $50 \mathrm{~mL}$ round bottomed flask equipped with a reflux condenser. The apparatus was then flame-dried and allowed to cool under $\mathrm{N}_{2}$. Tetrahydrofuran (16 mL) was added, followed by the dropwise addition of 4-bromoanisole $(6.2 \mathrm{~mL}, 50 \mathrm{mmol})$, such that gentle reflux could be maintained. The mixture was allowed to stir for $12 \mathrm{~h}$. Titration indicated a $2.27 \mathrm{M}$

(6) Breit, B.; Demel, P.; Studte, C. Angew. Chem., Int. Ed. 2004, 43, 3786-3789. 
solution of the Grignard reagent. (Note: Grignard reagent solution and syringe/needle must be kept warm during titration and addition because of the arylmetal low solubility in THF.)

An oven- and flame-dried $100 \mathrm{~mL}$ round bottomed flask (equipped with a stir bar) was charged with $\mathrm{ZnCl}_{2}$ (1.4 g, $10 \mathrm{mmol}$ ) weighed out under an $\mathrm{N}_{2}$ atmosphere; the flask was sealed with a septum and removed from the glovebox. Diethyl ether $(20 \mathrm{~mL})$ was added and the solution was allowed to cool to $0{ }^{\circ} \mathrm{C}$. A solution of the above-mentioned Grignard reagent $(8.8 \mathrm{~mL}, 20 \mathrm{mmol})$ was added dropwise through a syringe (within approximately $10 \mathrm{~min}$ ). During addition, a significant amount of white precipitate is generated. The mixture was allowed to warm to $22{ }^{\circ} \mathrm{C}$ and stir for $2 \mathrm{~h}$. At this time, the solution was charged with dioxane (10 mL) and allowed to stir for an additional $30 \mathrm{~min}$. (Note: $10 \mathrm{~mL}$ of THF can be added at this point if the solution containing $\mathrm{Zn}$ reagent appears too viscous for proper filtration.) At this point, an oven-dried Schlenk tube (medium porosity filter) containing approximately $5 \mathrm{~g}$ of oven-dried celite and a $100 \mathrm{~mL}$ round bottomed flask on the receiving end was quickly exchanged with the septum on the flask containing the $\mathrm{Zn}$ reagent. This was performed such that the round-bottomed flask containing the $\mathrm{Zn}$ reagent remained in a horizontal position; this ensured that celite does not fall into the flask that contains the zinc reagent Filtration was then performed under an atmosphere of $\mathrm{N}_{2}$. The filtrate was then concentrated in vacuo $(\sim 0.4 \mathrm{~mm} \mathrm{Hg})$, followed by gentle heating (still under vacuum; to assist in removal of dioxane) to afford a white solid. The white solid was transferred to a sublimation apparatus under an atmosphere of $\mathrm{N}_{2}$, and the white solid was sublimed under stronger vacuum $(0.01 \mathrm{mmHg})$ at $150{ }^{\circ} \mathrm{C}$ to afford a white powder. Note: The ${ }^{1} \mathrm{H}$ NMR of this material is identical to the ${ }^{1} \mathrm{H}$ NMR of the diarylzinc reagent prior to sublimation. We find that $\mathrm{Cu}$-catalyzed ACA with sublimed arylmetal samples deliver slightly higher levels of enantioselectivity. ${ }^{1} \mathrm{H}$ NMR $\left(400 \mathrm{MHz} \mathrm{CDCl}_{3}\right): \delta 7.57(4 \mathrm{H}, \mathrm{d}, J=8.4 \mathrm{~Hz}), 6.94(4 \mathrm{H}, \mathrm{d}, J=$ $8.8 \mathrm{~Hz}), 3.83(6 \mathrm{H}, \mathrm{s}) ;{ }^{13} \mathrm{C} \mathrm{NMR}\left(100 \mathrm{MHz}, \mathrm{CDCl}_{3}\right): \delta 160.1,139.2,138.5,114.0,55.1$. 


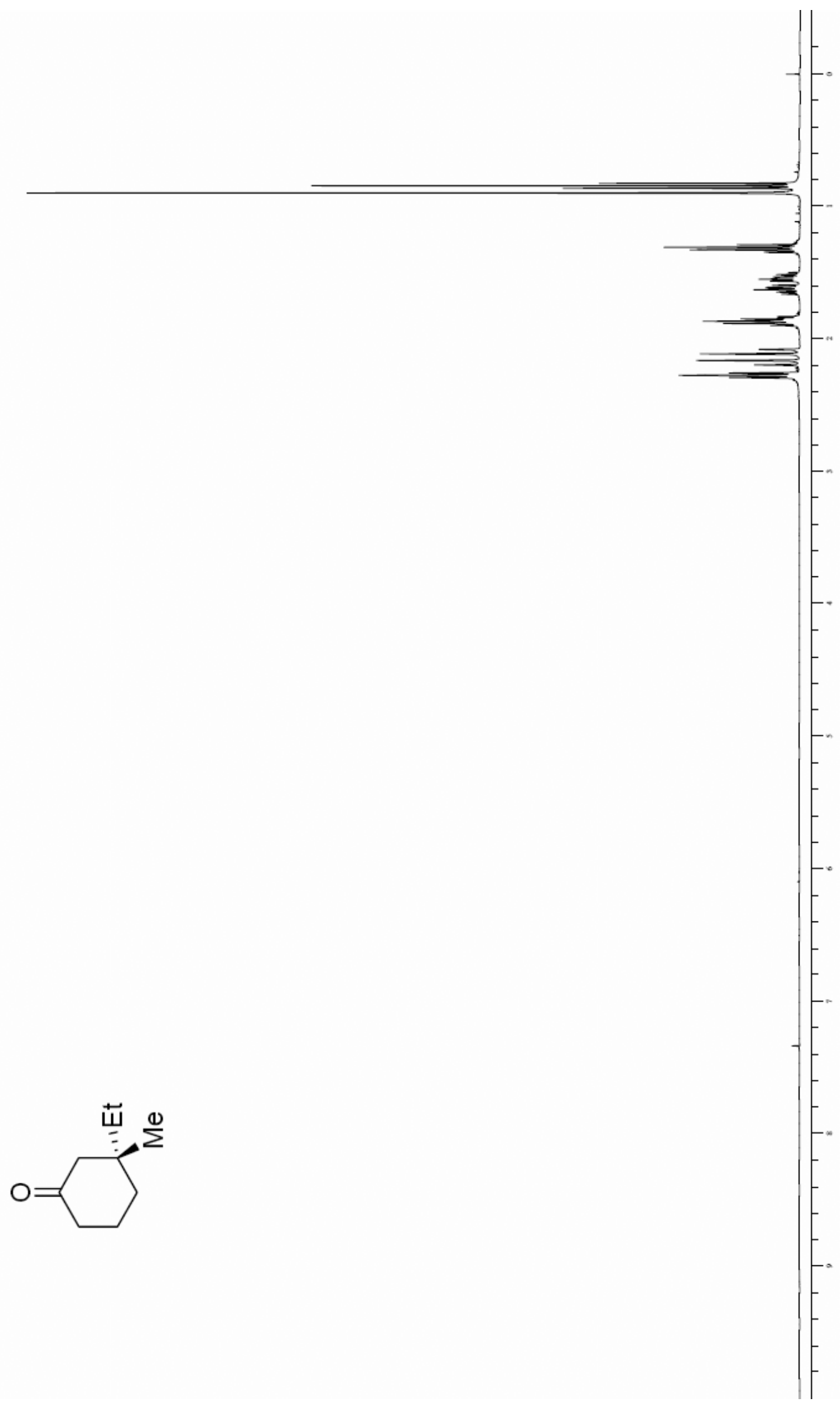


Lee, Brown, Hird \& Hoveyda, Supporting Information, Page S17

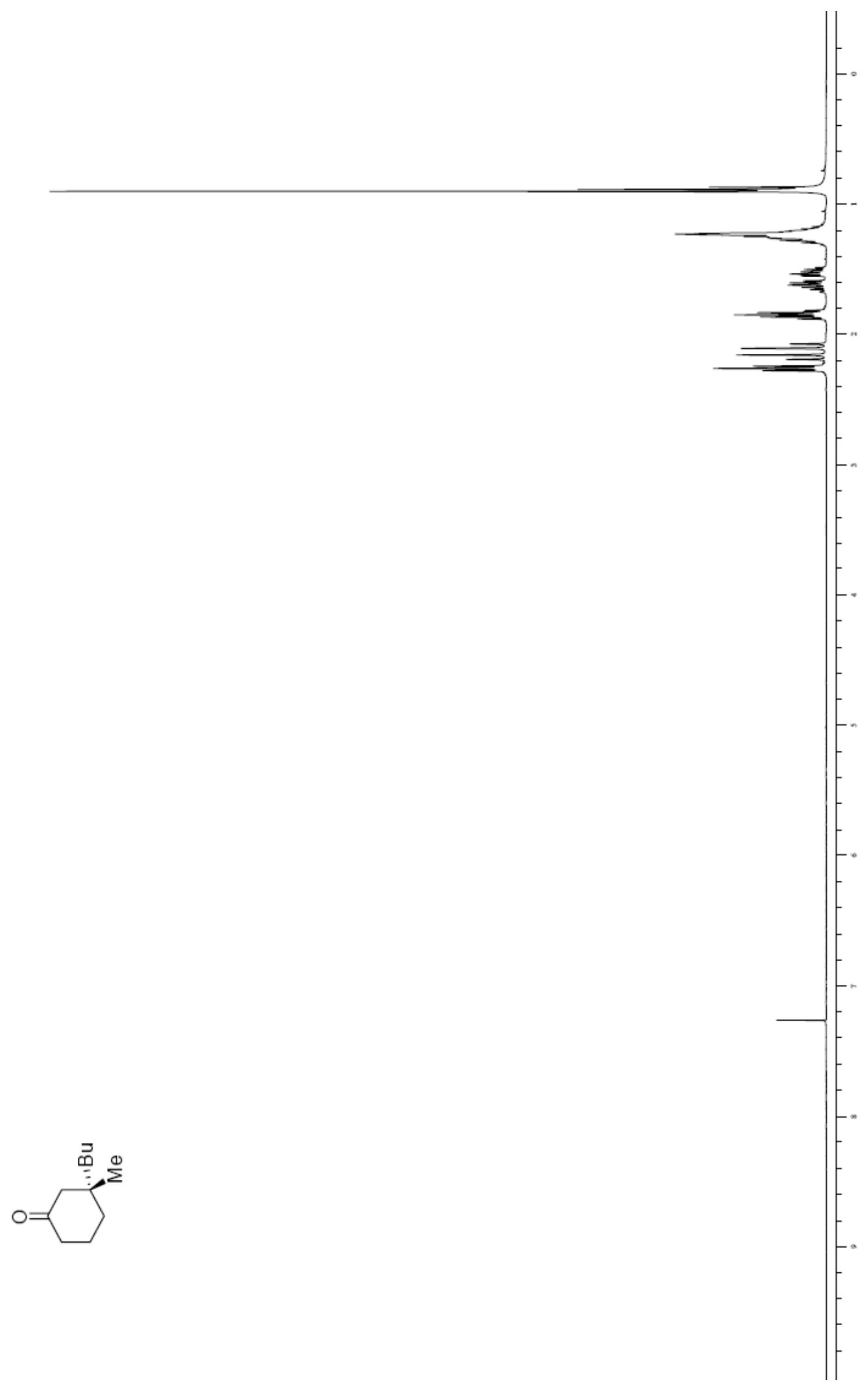




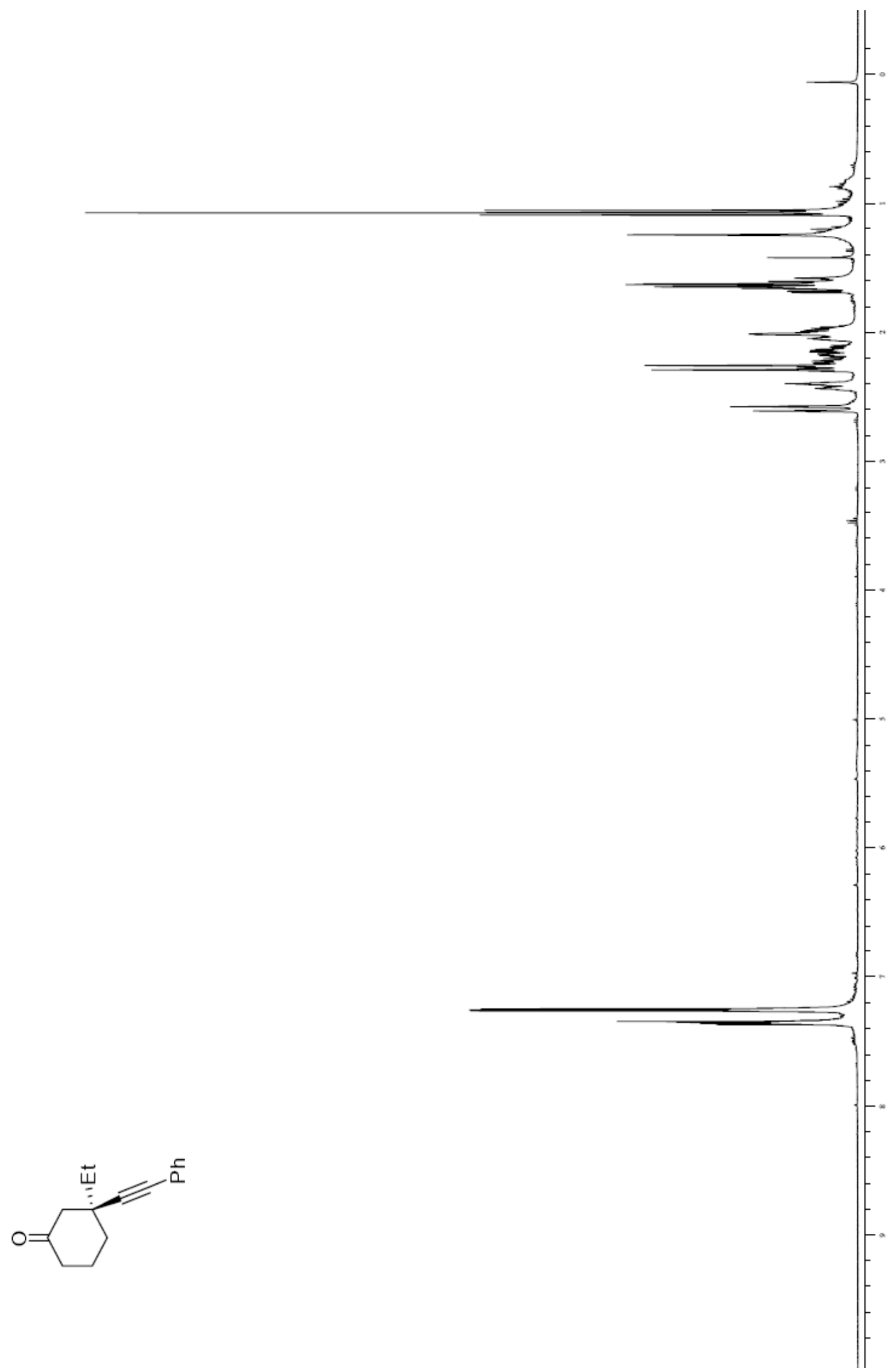




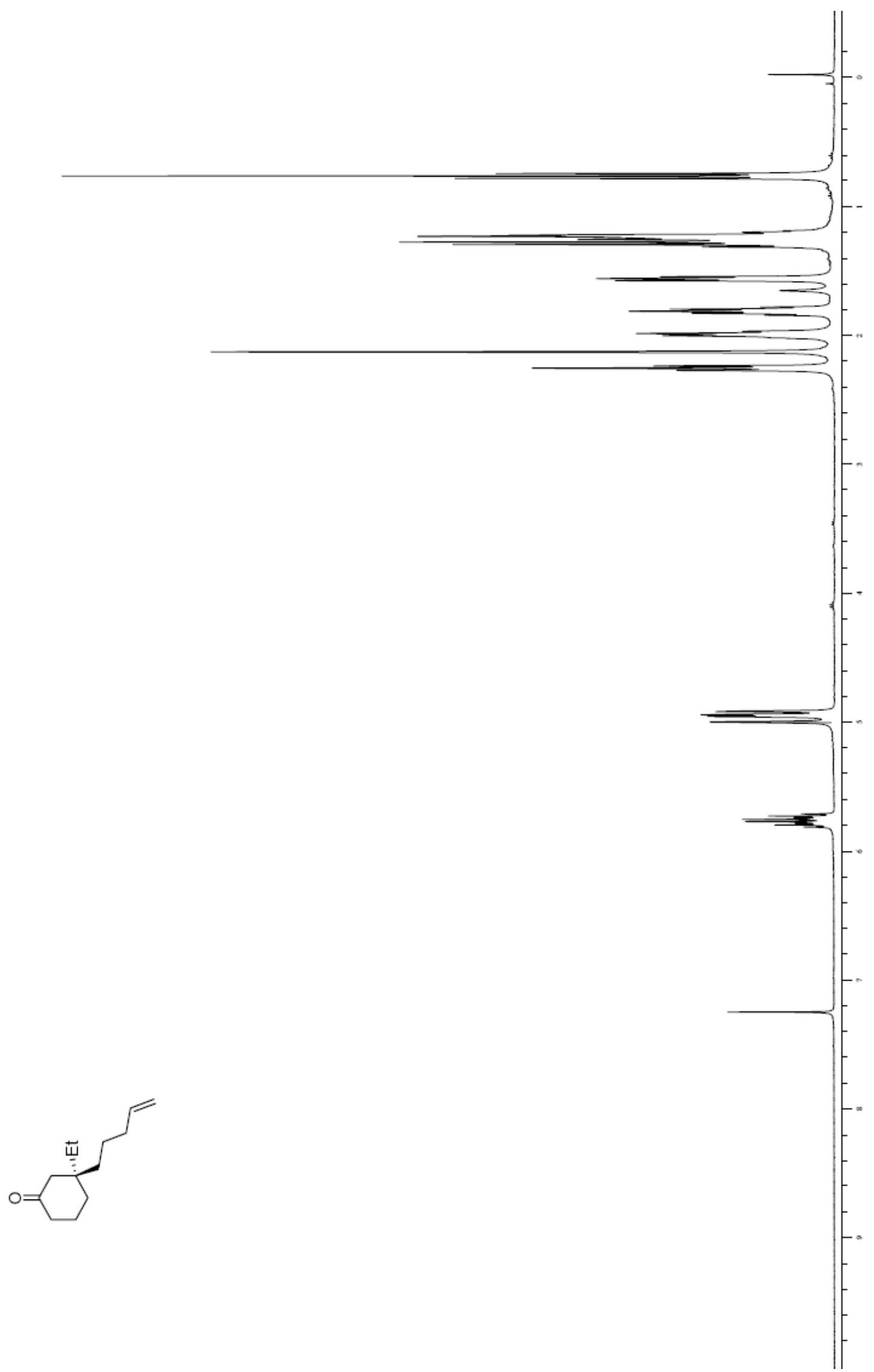




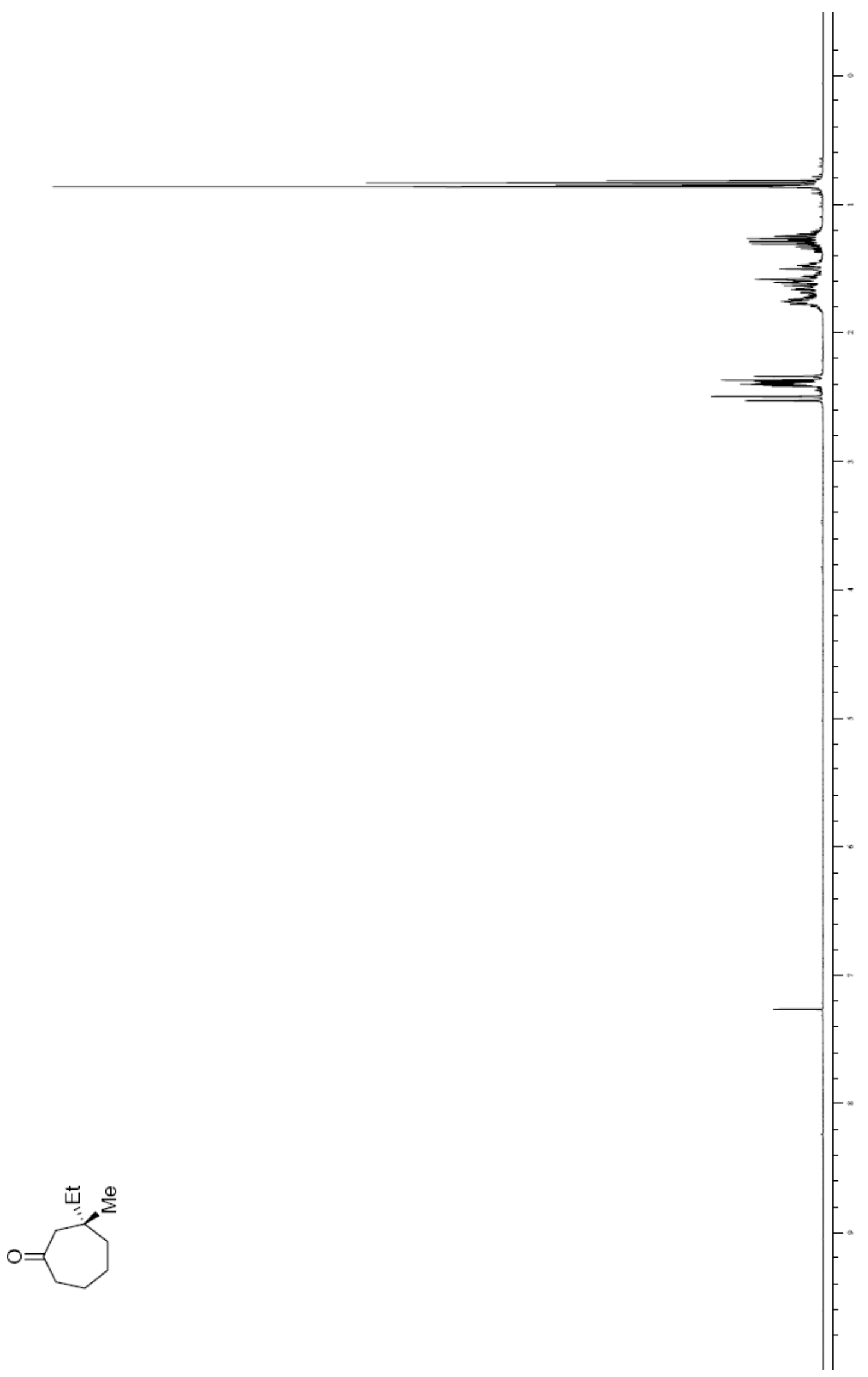


Lee, Brown, Hird \& Hoveyda, Supporting Information, Page S21

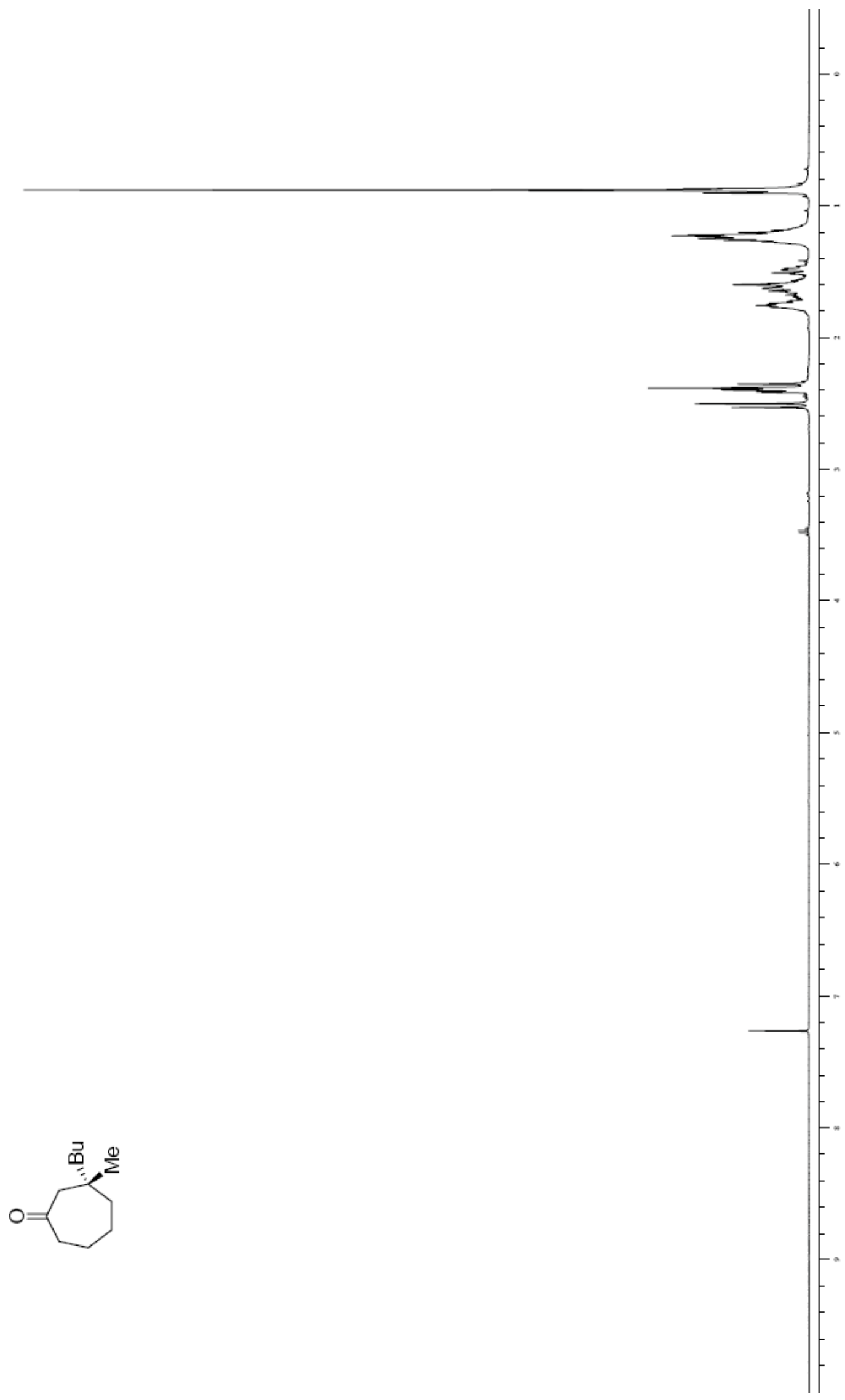




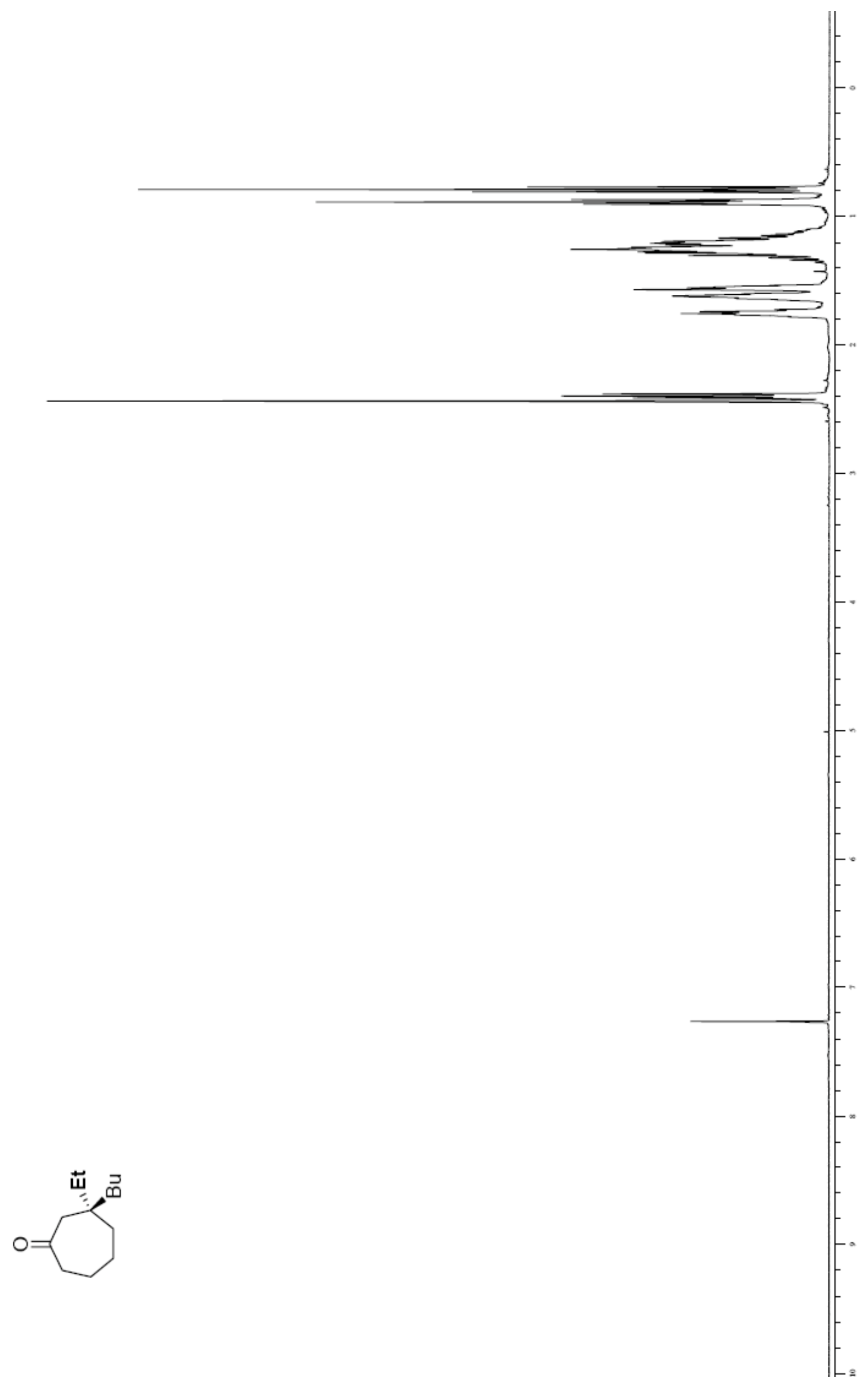


Lee, Brown, Hird \& Hoveyda, Supporting Information, Page S23

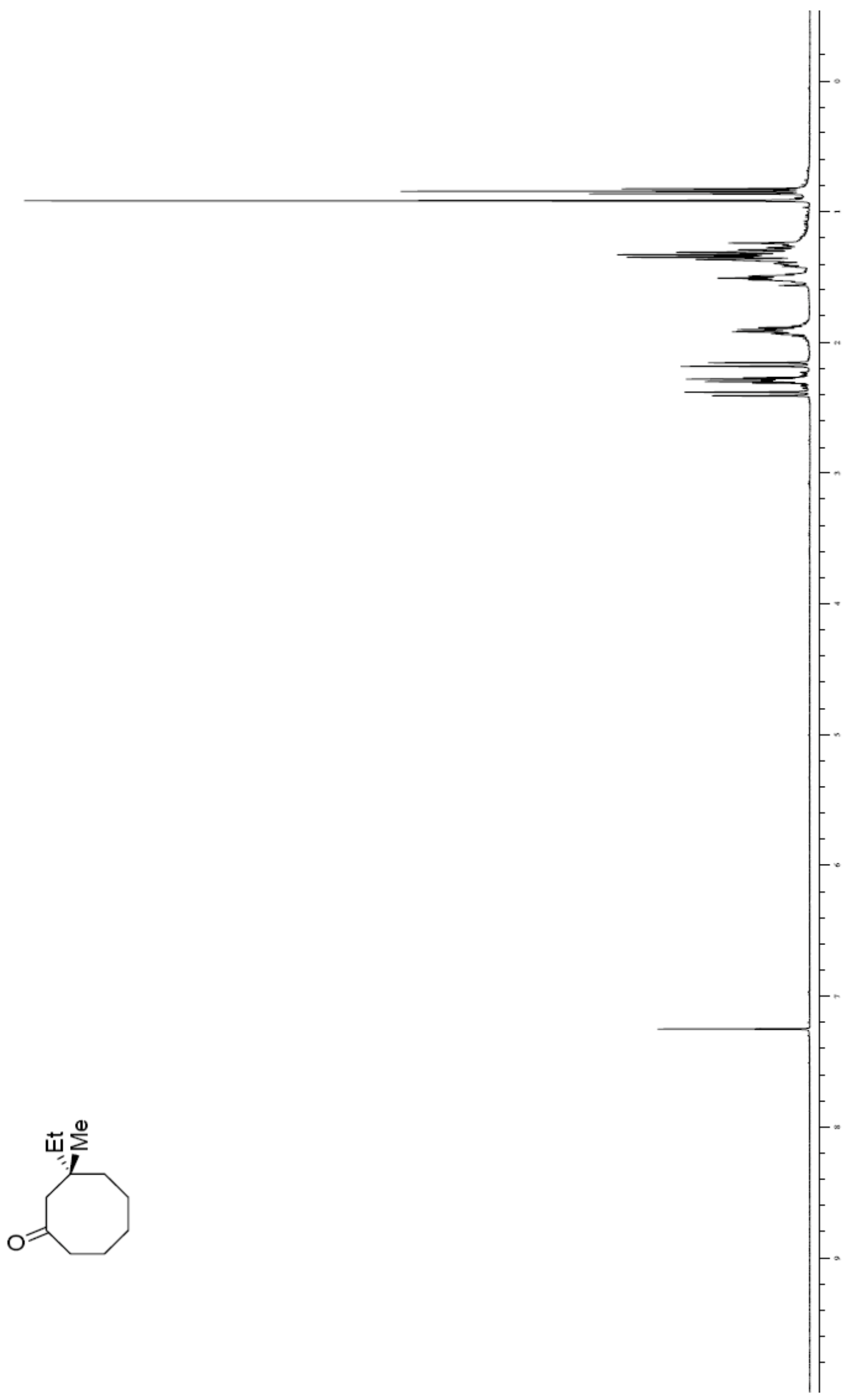




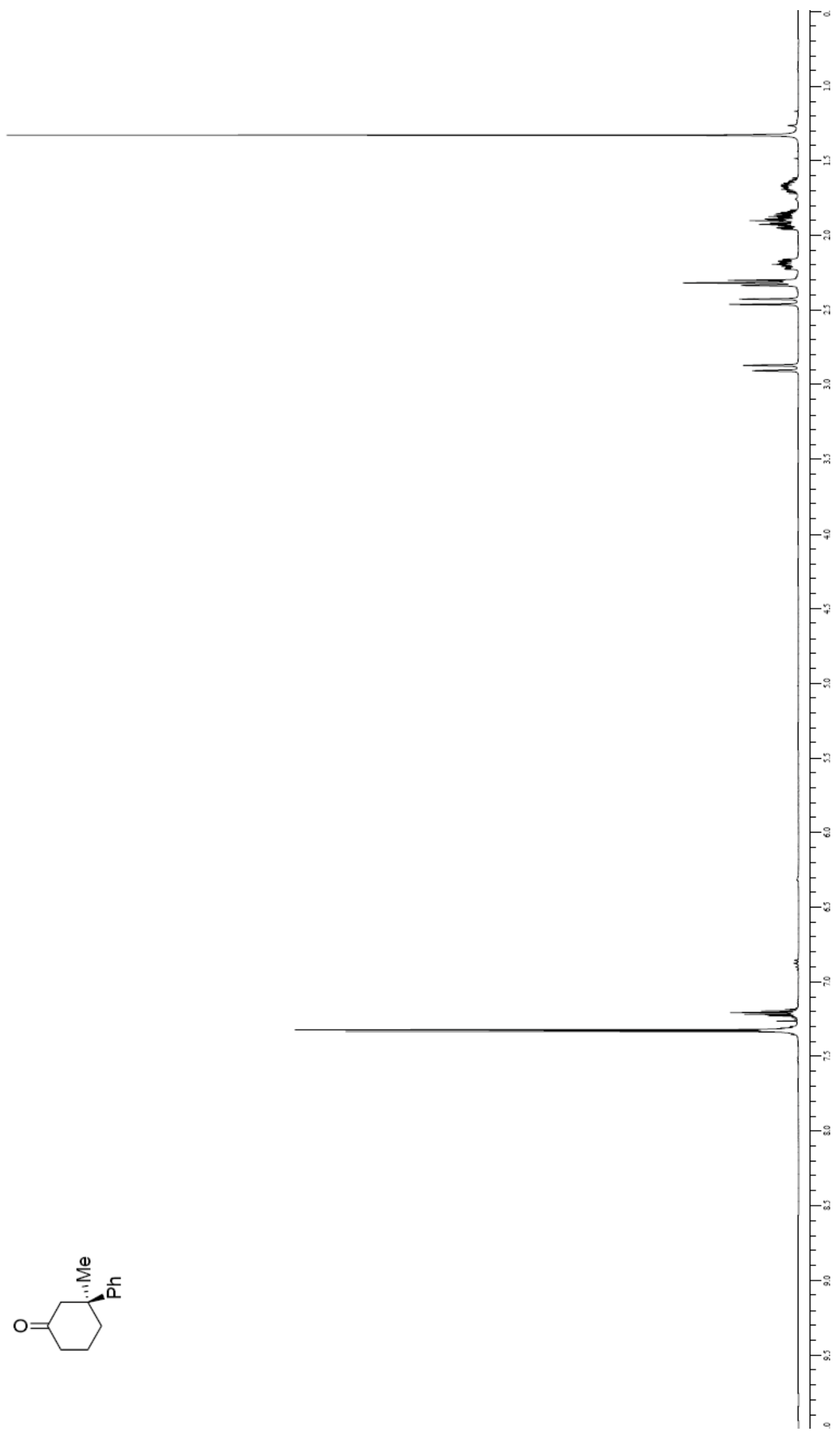




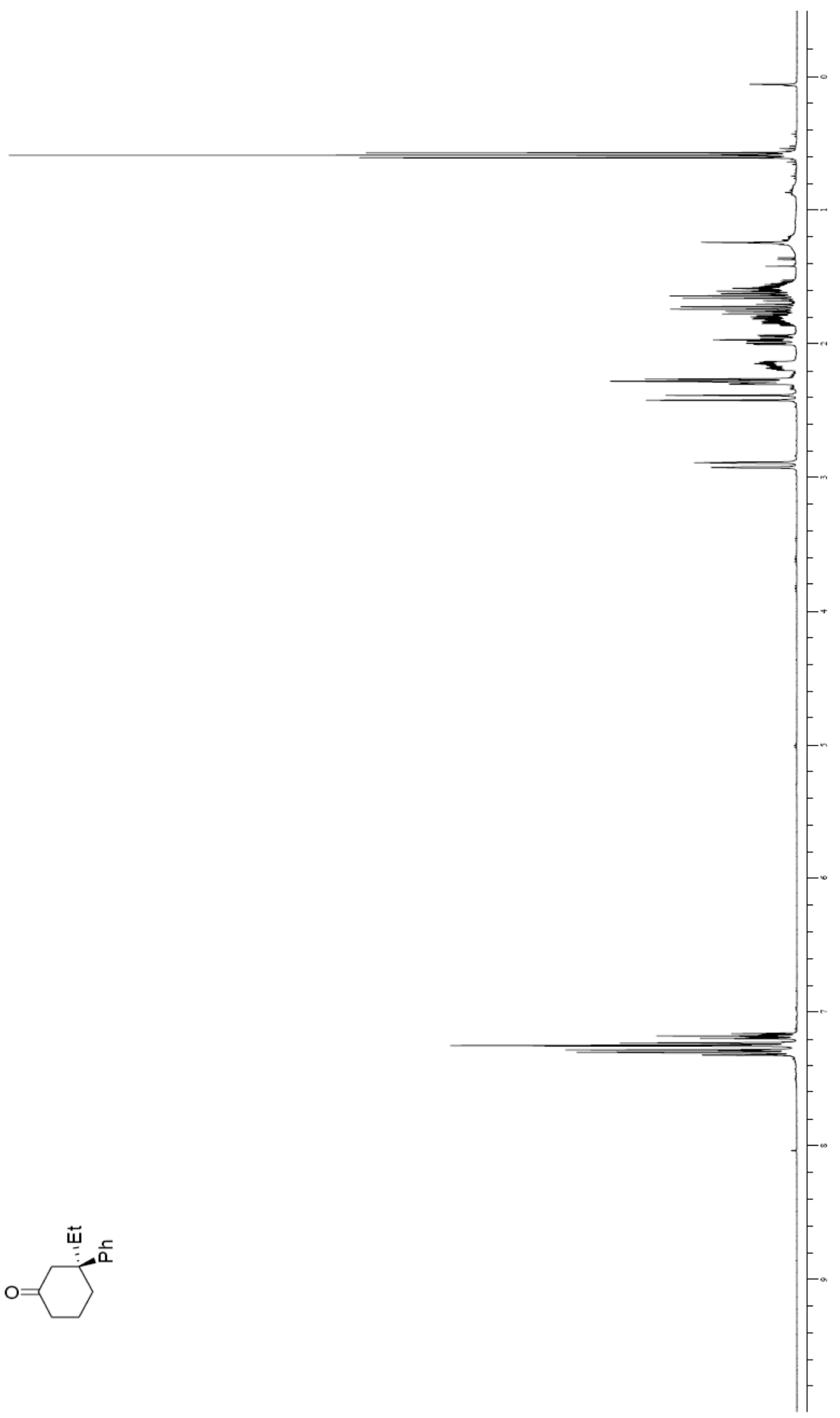




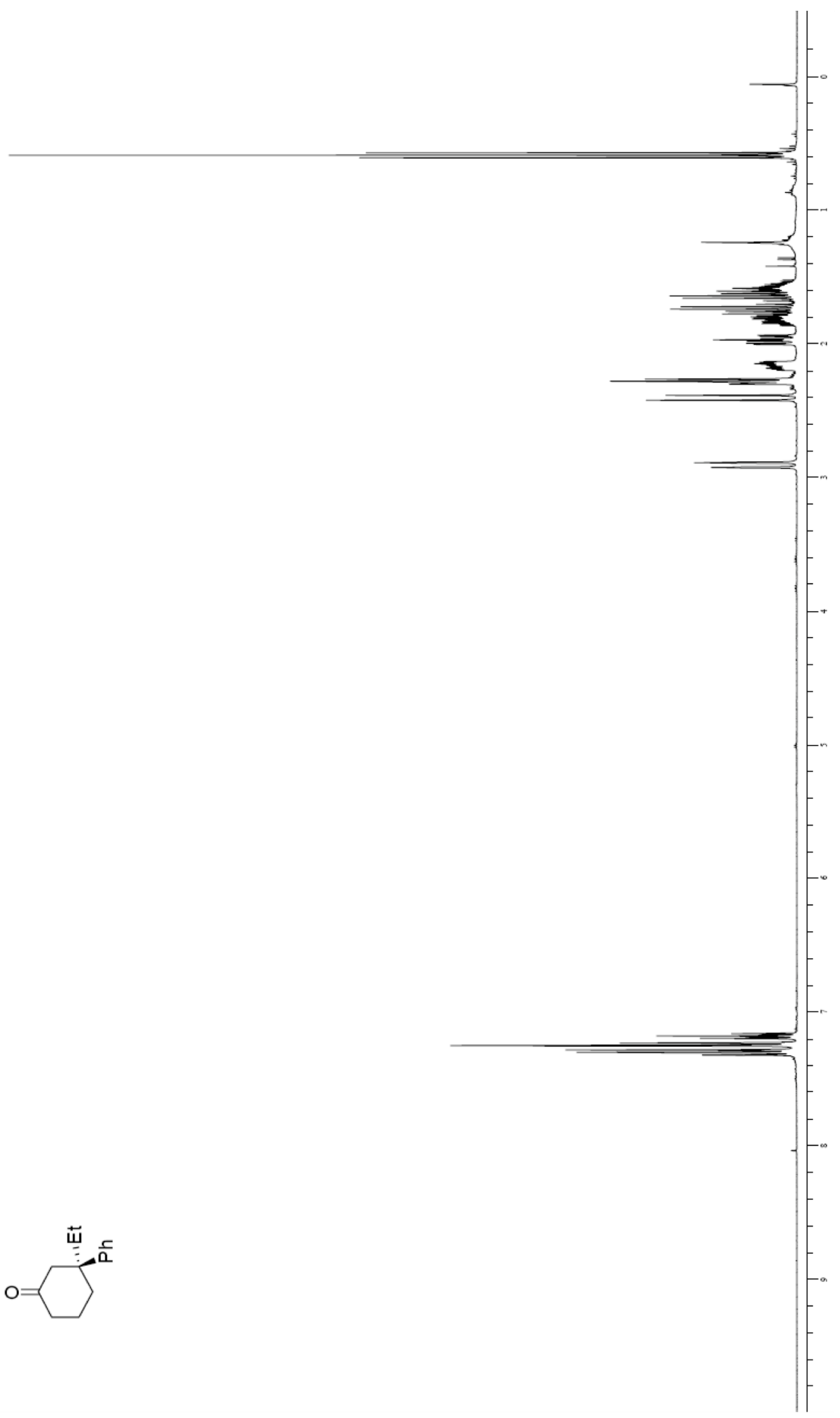




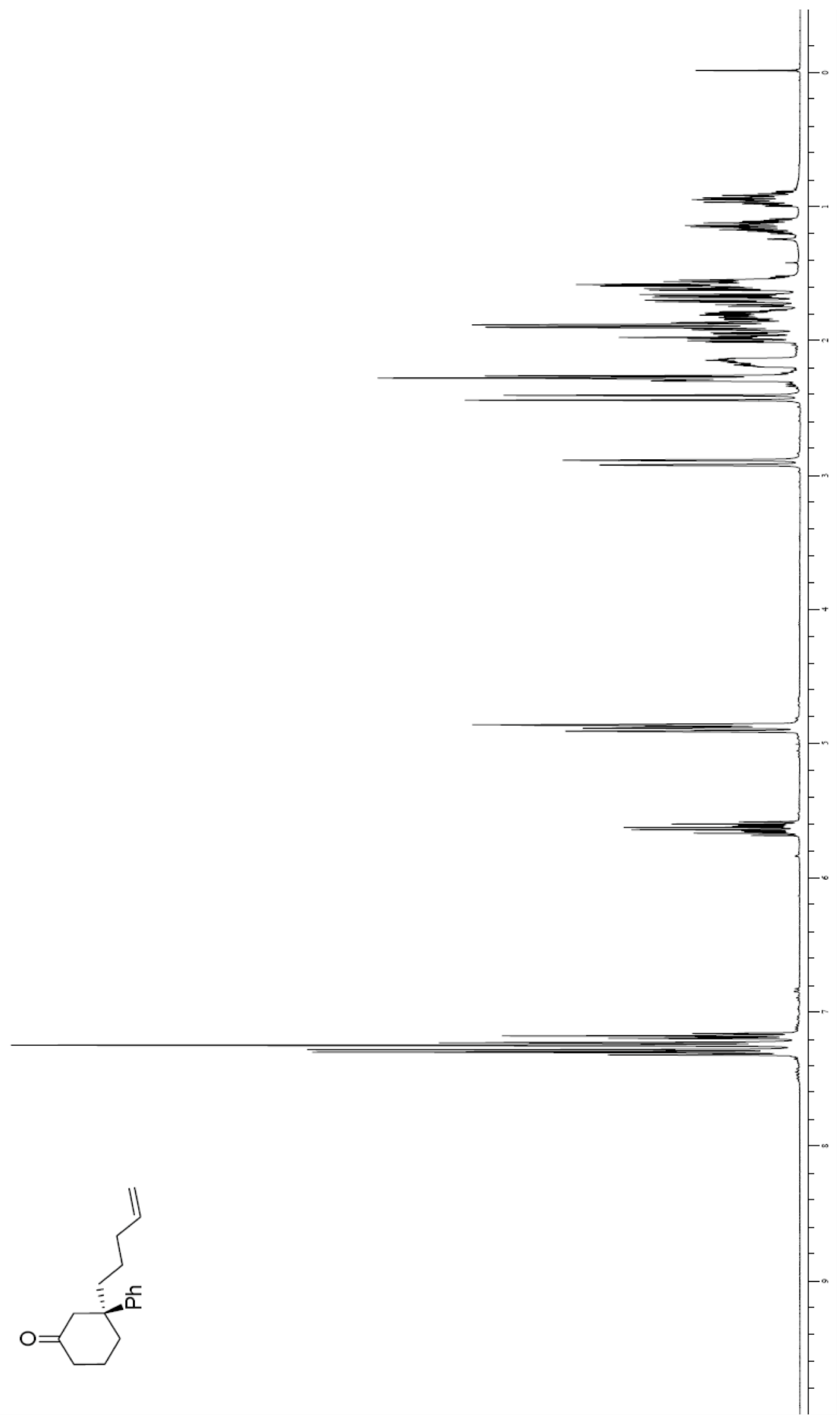




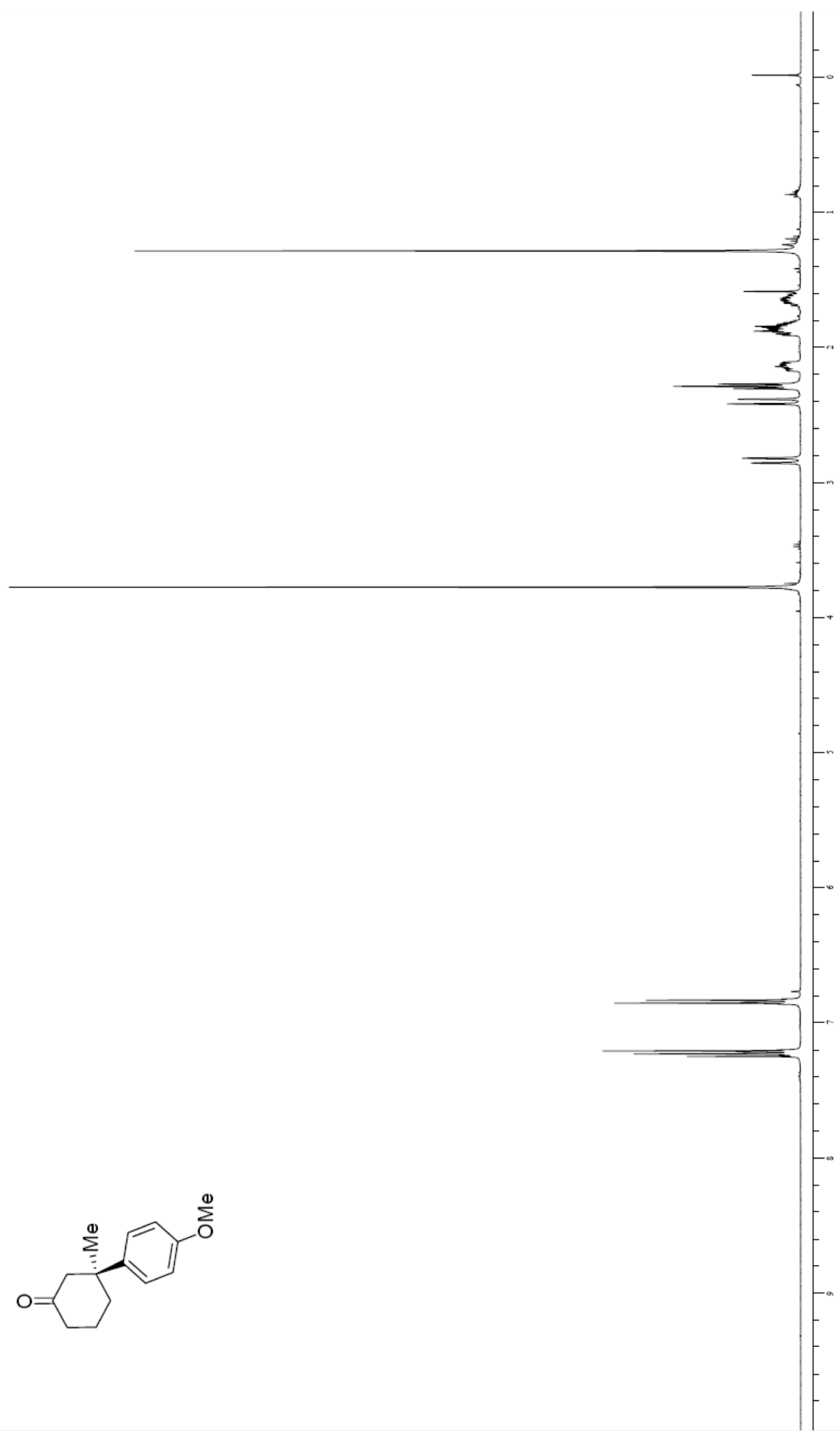


Lee, Brown, Hird \& Hoveyda, Supporting Information, Page S29

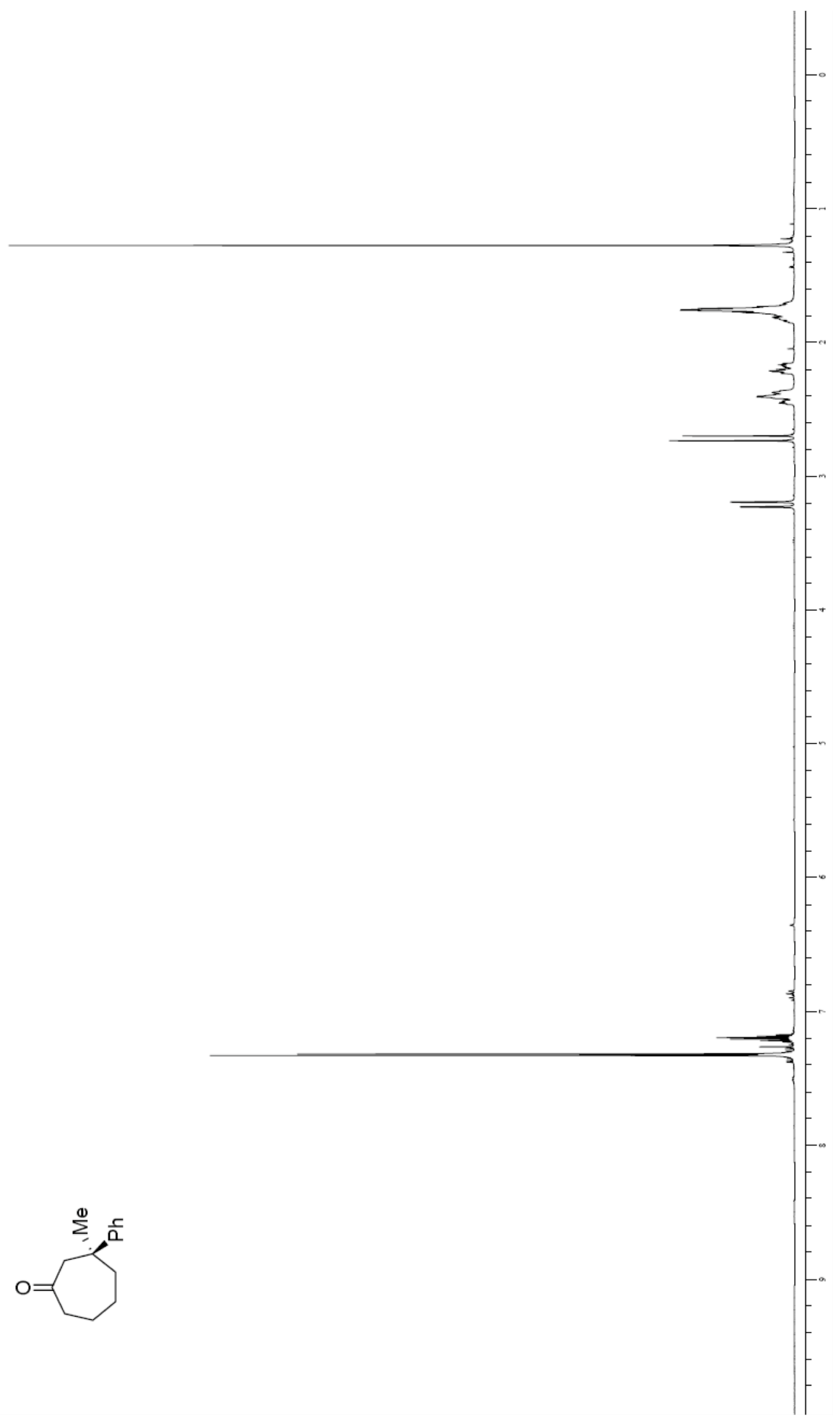


Lee, Brown, Hird \& Hoveyda, Supporting Information, Page S30

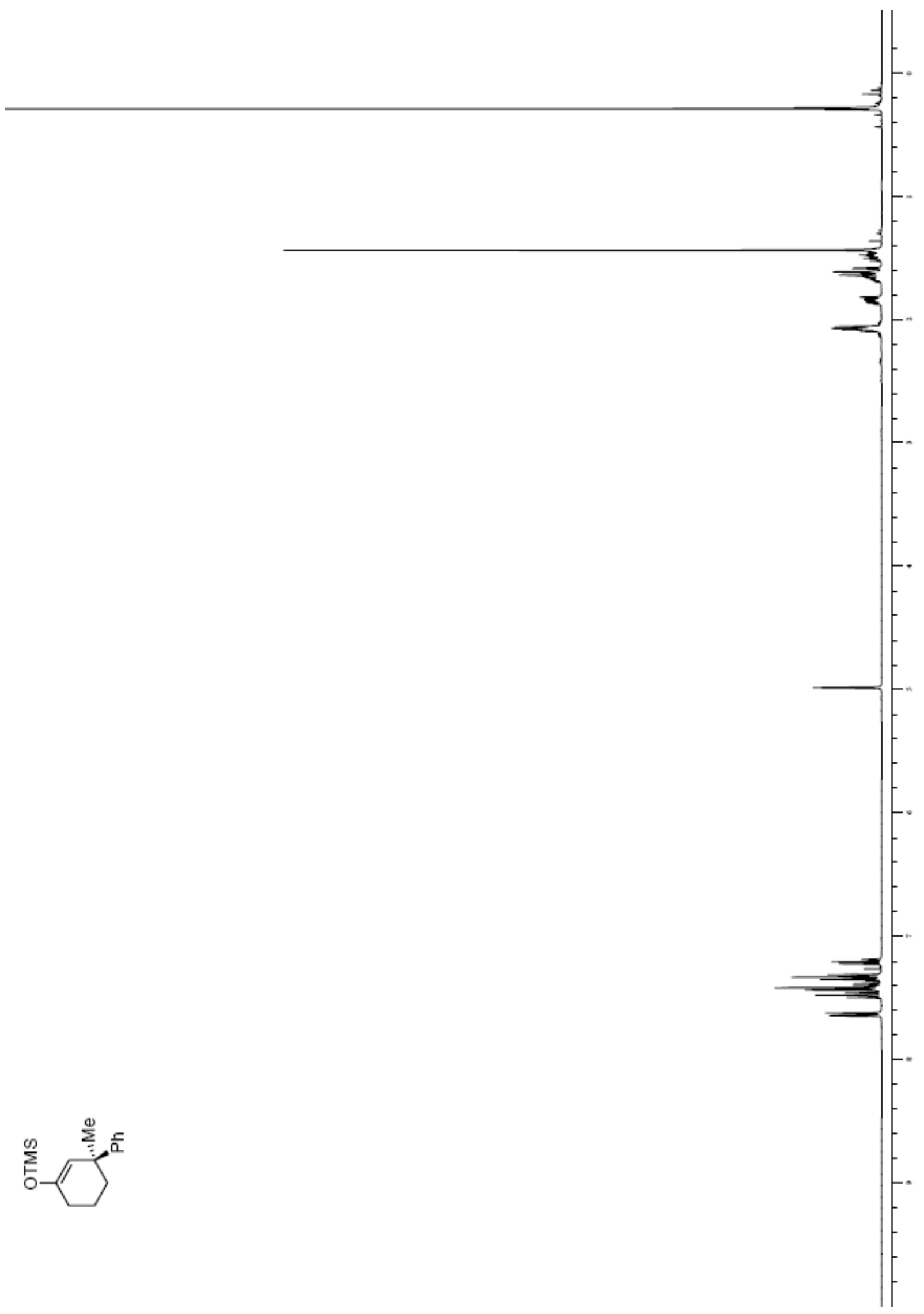


Lee, Brown, Hird \& Hoveyda, Supporting Information, Page S31

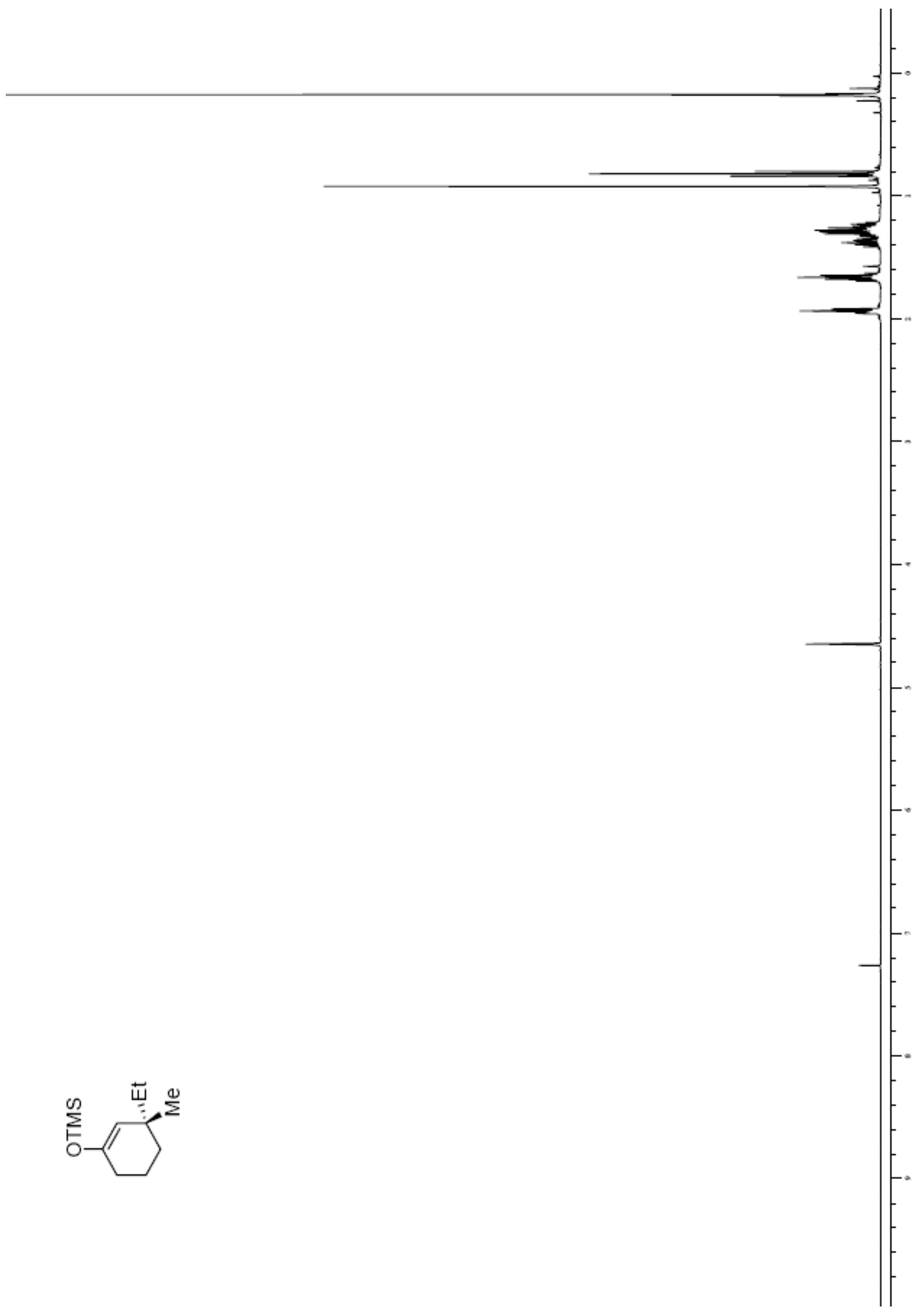


Lee, Brown, Hird \& Hoveyda, Supporting Information, Page S32

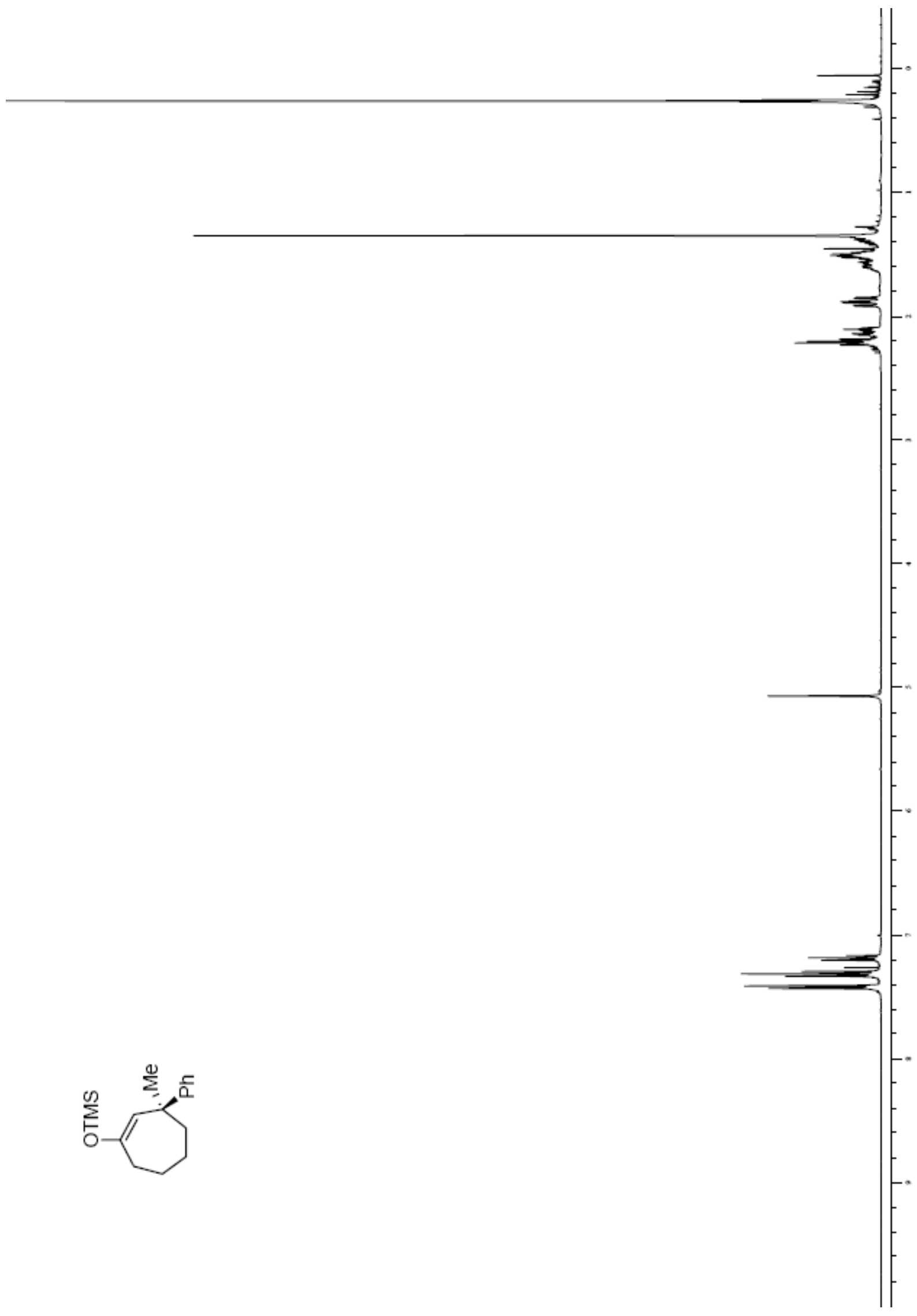




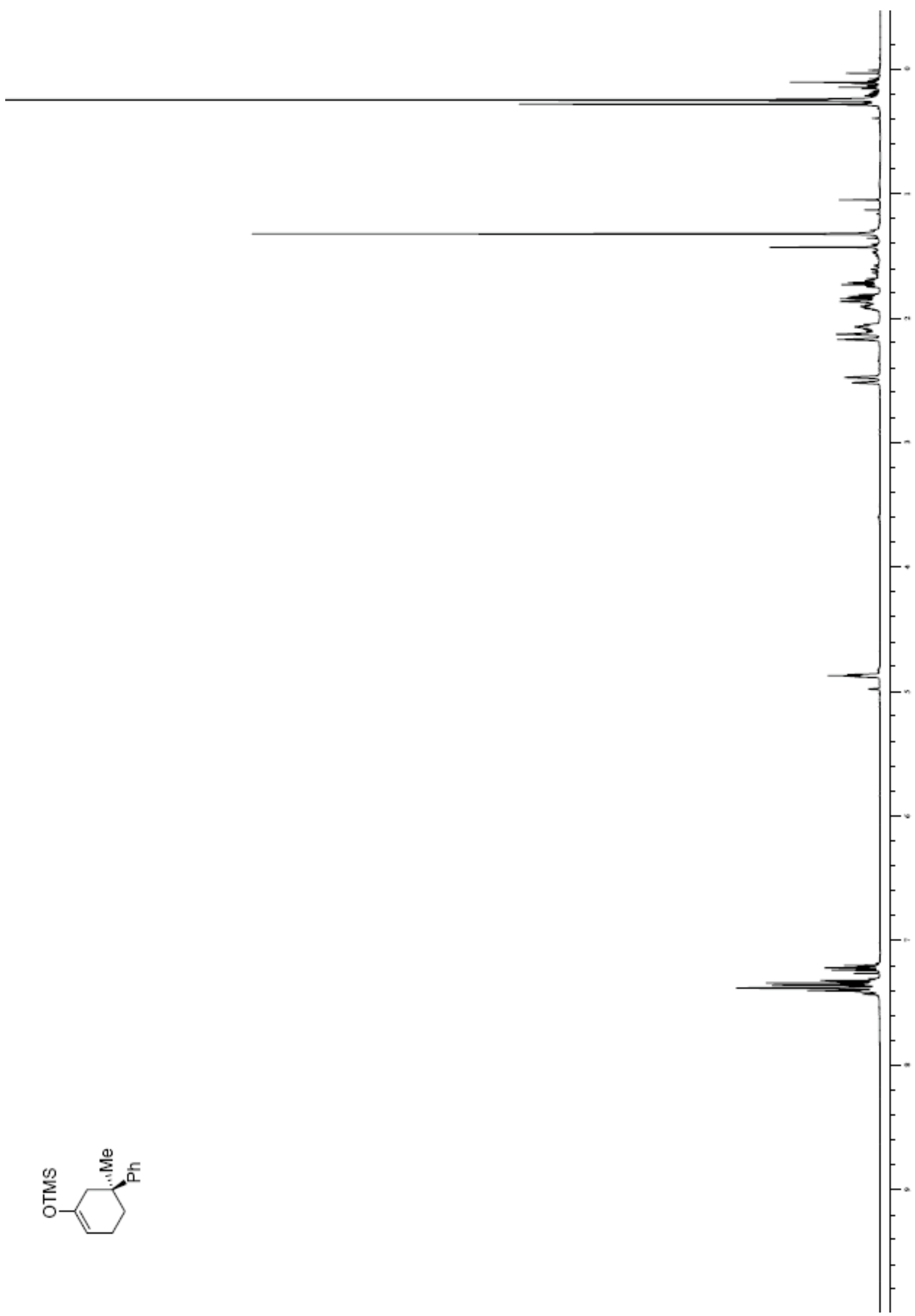

